UNIVERSITÀ

CATTOLICA

del Sacro Cuore

DIPARTIMENTO DI DISCIPLINE MATEMATICHE, FINANZA MATEMATICA ED ECONOMETRIA

WORKING PAPER N. 14/3

\title{
Expectations and Policies in Deflationary Recessions
}

Luca Colombo

Gerd Weinrich

VP VITA E PENSIERO 
Università Cattolica del Sacro Cuore

\section{DIPARTIMENTO DI DISCIPLINE MATEMATICHE, FINANZA MATEMATICA ED ECONOMETRIA}

WORKING PAPER N. 14/3

\section{Expectations and Policies in Deflationary Recessions}

Luca Colombo

Gerd Weinrich

\section{VP vita e pensiero}


Luca Colombo, Dipartimento di Economia e Finanza, Catholic University of Milan, Via Necchi 5, 20123 Milano, Italy.

Gerd Weinrich, Dipartimento di Discipline Matematiche, Finanza Matematica ed Econometria, Catholic University of Milan, Via Necchi 9, 20123 Milano, Italy.

\section{$\triangle$ lucava.colombo@unicatt.it \\ $\triangle$ gerd.weinrich@unicatt.it}

www.vitaepensiero.it

All rights reserved. Photocopies for personal use of the reader, not exceeding $15 \%$ of each volume, may be made under the payment of a copying fee to the SIAE, in accordance with the provisions of the law n. 633 of 22 April 1941 (art. 68, par. 4 and $5)$. Reproductions which are not intended for personal use may be only made with the written permission of CLEARedi, Centro Licenze e Autorizzazioni per le Riproduzioni Editoriali, Corso di Porta Romana n. 108, 20122 Milano, e-mail: autorizzazioni@clearedi.org,web site www.clearedi.org.

Le fotocopie per uso personale del lettore possono essere effettuate nei limiti del15\% di ciascun volume dietro pagamento alla SIAE del compenso previsto dall'art. 68, commi 4 e 5, della legge 22 aprile 1941 n. 633.

Le fotocopie effettuate per finalità di carattere professionale, economico o commerciale o comunque per uso diverso da quello personale possono essere effettuate a seguito di specifica autorizzazione rilasciata da CLEARedi, Centro Licenze e Autorizzazioni per le Riproduzioni Editoriali, Corso di Porta Romana n. 108, 20122 Milano, e-mail: autorizzazioni@clearedi.org, web site www.clearedi.org.

\section{(C) 2014 Luca Colombo, Gerd Weinrich ISBN 978-88-343-2889-7}




\begin{abstract}
In this paper we use a non-tâtonnement dynamic macroeconomic model to study the role of inventories, expectations and wages in the business cycle. Following a restrictive monetary shock, by amplifying spillover effects inventories may imply that the economy converges to a deflationary locally stable Keynesian underemployment state. The model is applied to evaluate economic policies like quantitative easing as well as the effectiveness of holding inflationary expectations to recover to full employment. If inflationary expectations are not sufficient, imposing downward rigidity of nominal wages helps to exit from the recession.
\end{abstract}

JEL classification: D45, D50, E32, E37

Keywords: deflationary recessions, expectations, nonneutrality of money, liquidity trap, quantitative easing

Financial support from the Italian national research project "Local interactions and global dynamics in economics and finance: models and tools", PRIN-2009, and from the Catholic University's research project "Teorie e modelli matematici per le scienze economiche", UCSC D.1, is gratefully acknowledged. 


\section{Introduction}

Why money affects output and why it has long lasting effects have long been central questions for the business cycle literature, if not for all of macroeconomics. This is especially so because, as stressed for instance by Blanchard (2000), the empirical evidence is irremediably at odds with the conclusions of the flex-price models. If prices were fully flexible, an increase in nominal money would immediately induce a proportional increase in the price level offsetting any pressure on demand and output, and money would be neutral even in the short run. Prices and wages, however, do not change instantaneously: they exhibit a certain degree of stickiness and individual price changes tend to be staggered, which makes the adjustment process of the price level more or less slow. During the process, aggregate demand and output are higher than their original values, and the change in the money stock has real effects. Eventually, most economists maintain, the price level will adjust proportionally to the increase in the nominal money stock, so that demand and output will be back at their original levels, and money neutrality will be restored. Before this occurs, real and nominal rigidities, lying behind the slow adjustment of prices and wages, are the causes of the temporary non-neutrality of money.

Since the beginning of the 1990s, the New Keynesian literature (see e.g. Ball and Romer, 1990, and Blanchard, 1987 and 1990) has emphasized that monetary shocks determine large aggregate effects when small frictions in nominal adjustment are supplemented by real rigidities. ${ }^{1}$ Attention has been devoted as well to the sources of nominal stickiness focusing, for instance, on

\footnotetext{
${ }^{1}$ Many causes of real rigidities have been investigated in the literature: among others, efficiency wages (see, for example, Solow, 1979, and Shapiro and Stiglitz, 1984), implicit contracts (Azariadis, 1975, and Baily, 1974), countercyclical mark-ups (Stiglitz, 1984, Rotemberg and Saloner, 1986, and Rotemberg and Woodford, 1991), inventories (Blinder, 1982), social customs (Akerlof, 1980, and Romer, 1984), strategic interactions and coordination failure (Ball and Romer, 1991), credit markets imperfections (Bernanke and Gertler, 1989 and 1995, Holmström and Tirole, 1997, 1998, and Kiyotaki and Moore, 1997) and increasing returns (Kiyotaki, 1988, and Diamond, 1982).
} 
menu cost or near rationality (e.g. Mankiw, 1985, and Akerlof and Yellen, 1985), staggered contracts (Calvo, 1983), optimal wage indexation by wage-setting trade unions in an economy subject to real and monetary shocks (Benassy, 1995), and uncertainty and risk aversion (Weinrich, 1997).

In this paper, we aim to show that both claims presented in the theoretical literature - about the long-run money neutrality and the effectiveness of price flexibility to lead the economy quickly back to the pre-shock state - do not necessarily hold. On the contrary, money can affect the output level in the long run and price and wage flexibility can foster this result, while wage rigidity may prove a good recipe to avoid or overcome permanent underemployment.

Our framework is a discrete-time dynamic non-tâtonnement macroeconomic model, building on Colombo and Weinrich (2003) and Bignami, Colombo and Weinrich (2004). The economy consists of an OLG consumption sector, a production sector and a government that finances public expenditure by means of a tax levied on firms' profits. Within each period prices are fixed and a consistent allocation is obtained by means of a temporary equilibrium with stochastic rationing whereas prices are adjusted between successive periods according to the strength of rationing or disequilibrium on each market in the previous period. ${ }^{2}$ This approach permits to account for the fact that in any economy with decentralized price setting the "adjustment of the general level of prices in terms of the numeraire is likely to be slow relative to a (fictional) economy with an auctioneer", as emphasized by Blan-

\footnotetext{
${ }^{2} \mathrm{~A}$ natural idea is to relate the adjustment of prices to the size of the dissatisfaction of agents with their (foregone) trades. A reliable measure of such a dissatisfaction requires stochastic rationing, since - as opposed to deterministic rationing - it is compatible with manipulability of the rationing mechanism and therefore provides an incentive for rationed agents to express demands that exceed their expected trades, as argued by Green (1980), Svensson (1980), Douglas Gale (1979, 1981), Honkapohja and Ito (1985) and Weinrich (1982, 1984, 1988). For a definition of manipulability see for example Böhm (1989) or Weinrich (1988).
} 
chard (2000, p. 1393). It is important to stress that the way we model the price/wage adjustment mechanism allows us to account quite naturally for different degrees of price and wage flexibility. Although our adjustment mechanism is given exogenously - and thus it may be considered ad hoc - it allows us to assess the impact of price and wage reactions to shocks generated by different underlying conceptual models. In other words, it is "agnostic" enough to provide a framework to study the impact of real and nominal rigidities in the New Keynesian tradition.

The novelty of the economy developed here with respect to the one considered in our previous papers is twofold. On the one hand, we abandon the simplifying assumption that there are no inventories. In the present paper, inventories are possible and stored goods may be sold in periods subsequent to the period of their production. Likewise, consumers may store goods bought in their first period of life to consume them in their second. More precisely, at the beginning of each period the stock of inventories carried by each firm is given by the firm's output that remains unsold at the end of the previous period. In this sense, inventories are not used as 'strategic' decision variables by firms which makes our treatment of inventories different from, and simpler than, most of the accounts present in the recent literature (see, for instance, Blinder and Fischer, 1981, and Blinder, 1982, where firms have a target inventory level and want to keep a certain inventories-to-sale ratio). However, in our model as well, the explicit consideration of inventories adds a further propagation mechanism for shocks and amplifies the importance of the spillover effects among markets.

On the other hand, and equally important, we look at the role that consumers' expectations play in explaining the persistence of shocks. The constructive approach by which we model them results in a truly forward looking dynamics with perfect foresight along any trajectory. If expectations are deflationary the economy may get stuck in an unemployment equilibrium, whereas if they are inflationary full employment is possible.

To highlight one of the main results of the paper where the two 
features discussed above play an important role, consider a restrictive monetary shock that, starting from a Walrasian equilibrium, reduces aggregate demand, inducing excess supply on the goods market and, consequently, a reduction in the goods price. The decrease in aggregate demand reduces labor demand and gives rise to an excess supply on the labor market as well, i.e. to Keynesian unemployment. Whenever the nominal wage is rigid downward, the real wage and the real money stock increase until the economy leaves the state of Keynesian unemployment to enter a state of Classical unemployment, that is excess demand on the goods market and excess supply on the labor market. At this point the goods price starts to increase again, determining a reduction of the real wage and of the real money stock until the economy converges back to a full-employment equilibrium.

The process changes quite dramatically when there is downward wage flexibility. In this case, the monetary shock determines a reduction of the nominal wage that, if it is large enough, implies a decrease of the real wage, too. ${ }^{3}$ The presence of inventories significantly reinforces this reduction, by increasing the fall of labor demand, which in turn depresses labor income and aggregate demand. The real wage continues to fall, although ever more slowly. Eventually the economy converges to a quasi-stationary Keynesian state with a constant low real wage, permanent unemployment and permanent deflation of the nominal variables. ${ }^{4}$ Therefore downward nominal wage flexibility favors a lasting impact of monetary shocks whereas imposing downward nominal wage rigidity appears to be a viable policy to prevent the emergence of deflationary recessions or at least limit their extent and duration.

Moreover, we suggest, by means of numerical simulations, that such recessionary quasi-stationary equilibria are locally stable while the stationary Walrasian equilibrium is unstable. Specifically, re-

\footnotetext{
${ }^{3}$ As discussed in Section 7 , in Japan over several years a decrease both of the nominal wage and of prices did result in a repeated decrease of the real wage.

${ }^{4}$ Quasi-stationary means constant real but varying nominal variables.
} 
ductions in the real money stock or in real profits, and increases in the stock of inventories, destroy the full employment equilibrium and cause the economy to converge to a quasi-stationary Keynesian equilibrium.

Besides the theoretical underpinnings on the role and consequences of inventories and expectations dynamics the paper is, as we think, of interest in a policy perspective. Our setup is, in fact, able to account for the dynamic behavior of economies that are trapped in situations of underemployment or underutilization of the productive capacity. This proves useful in evaluating the impact of alternative policy measures aimed at restoring full employment. In this respect, we use our economy as a test bank to investigate the prolonged deflationary behavior of the Japanese economy since the early 1990s and to evaluate the performance of different monetary policies designed to stimulate the economy. More precisely, the recessionary Keynesian equilibrium of our economy seems to reproduce quite well the essential features of the Japanese deflation, providing a suitable framework to discuss the impact of different economic policies. In particular, we focus on policy measures requiring simultaneous fiscal and monetary expansionary stimuli based on tax cuts directly financed by the central bank to check whether they are effective in restoring full employment in our model economy. ${ }^{5}$ By operating a reduction of the tax rate and maintaining unchanged both the government's budget deficit and, by means of a monetary expansion, aggregate demand, our analysis suggests that the stationary long-run employment level increases monotonically with the decrease in the tax rate. This confirms the efficacy of such policies that, provided they are of the right magnitude, should be capable to restore full employment. ${ }^{6}$

\footnotetext{
${ }^{5}$ Similar policies have been implemented by the Bank of Japan, which has adopted a policy of quantitative monetary easing since 2001. Policies equivalent to those outlined in the paper have also been advocated by Ben Bernanke (see The Economist, June 21st, 2003).

${ }^{6}$ These policies have been called for by many economists (see e.g Auerbach and Obstfeld, 2005) and lie at the heart of the so-called 'Abenomics',
} 
Finally, the paper also provides a setup to investigate the role of consumers' expectations in economies experiencing prolonged recessions. In a series of influential policy papers and editorials of the end of the 1990s, investigating the liquidity trap situation of the Japanese economy, Paul Krugman advocated the importance of creating inflationary expectations to escape the recession. ${ }^{7} \mathrm{We}$ discuss under what conditions such a 'policy' works in our framework, and study the relationships between expectations and the degree of wage and price stickiness/flexibility characterizing the economy. In particular, we show that after a restrictive monetary shock leading to a deflationary recession, and provided the latter is not too deep, the economy can recover to full employment if consumers can be convinced to hold inflationary expectations. By expecting inflation for the next period and being able to store the consumption good so that they can consume part of it in their second period of life, consumers have an incentive to demand all their desired life-time consumption when young, which boosts aggregate demand potentially allowing the economy to get out of the recession.

It is essential to note, however, that the degree of wage stickiness matters for the ability of the economy to recover from a recession through inflationary expectations. For sufficiently high downward flexibility of the nominal wage, in fact, the increase in aggregate demand determined by the anticipated purchases induced by inflationary expectations is not enough to lead the economy out of the recession, and expectations quickly return from inflationary to deflationary. On the contrary, for low values of wage flexibility, inflationary expectations suffice to restore full employment. Finally, for intermediate values of downward nominal wage flexibility, multiplicity of equilibria with self-confirming (deflationary or inflationary) expectations will emerge. This suggests that,

which places a large emphasis on quantitative easing to alleviate deflationary pressures.

${ }^{7}$ Most of Krugman's papers on this subject have been collected in a special page on Japan of Krugman's website at http://web.mit.edu/krugman/www/. 
in the case in which inflationary expectations are not sufficient to overcome the recession, imposing downward rigidity of wages is an effective measure to restore full employment.

The remainder of the paper is organized as follows. Section 2 presents the behavior of consumers, producers and the government, and it discusses the timing of the model. Section 3 defines the temporary equilibrium with stochastic rationing of the economy and proves the existence and uniqueness of such an equilibrium. In Section 4 we set up the dynamic system, illustrating the behavior of the state variables, and the adjustment processes of prices and wages. We also introduce the possibility of expectations switching in order to keep expectations correct along a trajectory of the system. Section 5 presents numerical simulations of the behavior of the economy and illustrates the consequences of a restrictive monetary shock for different degrees of wage and price stickiness, while Section 6 asserts the local stability of the quasi-stationary recessionary and inflationary equilibria, as well as the instability of Walrasian equilibrium. Section 7 investigates the effectiveness of alternative economic policies to recover from a deflationary recession, focusing on the case of an economy in a liquidity trap situation (such as that experienced by Japan for more than two decades by now), for which traditional fiscal or monetary policies are difficult to implement. In particular, we explore the potential of both expansionary fiscal and monetary policies and of policies based on the creation of inflationary expectations, as well as the effects of changes in the degree of wage stickiness or flexibility. Section 8 concludes and two appendices contain more technical material.

\section{The Model}

We consider an economy in which there are $n$ OLG-consumers, $n^{\prime}$ firms and a government. Consumers offer labor inelastically when young and consume a composite consumption good in both periods. That good is produced by firms using an atemporal pro- 
duction function whose only input is labor. The government levies a proportional tax on firms' profits to finance its expenditure for goods. Nevertheless, budget deficits and surpluses may arise and are made possible through money creation or destruction.

\subsection{Timing of the Model}

In period $t-1$ producers obtain an aggregate profit of $\Pi_{t-1}$, which is distributed at the beginning of period $t$ in part as tax to the government $\left(\operatorname{tax} \Pi_{t-1}\right)$ and in part to young consumers $\left((1-\operatorname{tax}) \Pi_{t-1}\right)$, where $0 \leq \operatorname{tax} \leq 1 .^{8}$ Also at the beginning of period $t$ old consumers hold a total quantity of money $M_{t}$, consisting of savings generated in period $t-1$. Thus households use money as a means of transfer of purchasing power between periods.

Let $X_{t}$ denote the aggregate quantity of the good purchased by young consumers in period $t, p_{t}$ its price, $w_{t}$ the nominal wage and $L_{t}$ the aggregate quantity of labor. Then

$$
M_{t+1}=(1-\operatorname{tax}) \Pi_{t-1}+w_{t} L_{t}-p_{t} X_{t} .
$$

Denoting with $G$ the quantity of goods purchased by the government and taking into account that old households want to consume all their money holdings in period $t$, the aggregate consumption of young and old households and of the government is $Y_{t}=X_{t}+M_{t} / p_{t}+G$. Using that $\Pi_{t}=p_{t} Y_{t}-w_{t} L_{t}$, considering $\Pi_{t}-\Pi_{t-1}=\Delta M_{t}^{P}$ as the variation in the money stock held by producers before they distribute profits and denoting with $\Delta M_{t}^{C}=M_{t+1}-M_{t}$ the one referring to consumers, we obtain a standard accounting identity, i.e. $\Delta M_{t}^{C}+\Delta M_{t}^{P}=p_{t} G-\operatorname{tax} \Pi_{t-1}$, the latter being the budget deficit.

Denoting with $S_{t}$ the aggregate amount of inventories carried over by firms to period $t$ and with $Y_{t}^{p}$ the aggregate amount of goods produced in period $t$, there results $S_{t+1}=Y_{t}^{p}+S_{t}-Y_{t}$.

\footnotetext{
${ }^{8}$ This assumption can be seen as encoding the idea that consumers are dynasties who own the technology. Young consumers collect the profits and when old give the property rights to the next generation.
} 


\subsection{The Consumption Sector}

Young consumers are endowed with $\ell^{s}$ units of labor and an amount of money $(1-\operatorname{tax}) \Pi_{t-1} / n$. Preferences will be described by an expected utility function derived from the instantaneous utility function $u\left(x_{t}, x_{t+1}\right)=x_{t}^{h} x_{t+1}^{1-h}, 0<h<1$, where $x$ denotes consumption. ${ }^{9}$ In solving its decision problem the young household has to decide whether to buy the quantities $x_{t}$ and $x_{t+1}$ in periods $t$ and $t+1$, respectively, or buy the total quantity $x_{t}+x_{t+1}$ in period $t$ and transfer (costlessly) $x_{t+1}$ to period $t+1$. This in turn depends on the value of $\theta_{t}^{e} \equiv p_{t+1}^{e} / p_{t}$ where the superscript $e$ stands for expectation. If $\theta_{t}^{e}<1$, the consumer expects a decrease in the goods price and hence prefers to buy $x_{t+1}$ in his second period of life. In the opposite case $\theta_{t}^{e}>1$ he buys everything in his first period.

Consider first the case $\theta_{t}^{e}<1$. We assume that the labor market is visited before the goods market and that young consumers may be rationed on the labor market, according to a $0-1$ rationing mechanism. Then they face the budget constraints

$$
0 \leq x_{t} \leq \omega_{t}^{i}, 0 \leq x_{t+1} \leq\left(\omega_{t}^{i}-x_{t}\right) / \theta_{t}^{e}, i=0,1,
$$

where

$$
\omega_{t}^{0}=\frac{1-\operatorname{tax}}{p_{t}} \frac{\Pi_{t-1}}{n} \quad \text { and } \quad \omega_{t}^{1}=\omega_{t}^{0}+\frac{w_{t}}{p_{t}} \ell^{s}
$$

are a consumer's real wealth when he is unemployed and employed, respectively.

A young consumer may be rationed, again according to a $0-1$ rule, also on the goods market. ${ }^{10}$ The expected value of consumption is $\gamma_{t}^{d} x_{t}^{d}$, where the rationing coefficient $\gamma_{t}^{d} \in[0,1]$ is the probability that he can buy his quantity demanded $x_{t}^{d}$. It is perceived as given by the consumer but will be determined in equilibrium. From these assumptions follows that expected utility

\footnotetext{
${ }^{9}$ See Colombo and Weinrich (2003) for a more general approach to the consumer's problem.

${ }^{10}$ The $0-1$ rule is for simplicity only. For a more general formulation see Colombo and Weinrich (2003).
} 
is $\gamma_{t}^{d} x_{t}^{h}\left(\left(\omega_{t}^{i}-x_{t}\right) / \theta_{t}^{e}\right)^{1-h}$ the maximization of which yields the effective demand $x_{t}^{d i}$ equal to $h \omega_{t}^{i}$, which obviously depends on the real income $\omega_{t}^{i}$, and hence on whether the consumer has been employed, but it is independent of $\gamma_{t}^{d}$ and $\theta_{t}^{e}{ }^{11}$

Consider now the case $\theta_{t}^{e}>1$. Then a young consumer wants to buy the total quantity $x_{t}+x_{t+1} \equiv \widehat{x}_{t}$ in his first period of life and thus has to meet the budget constraint

$$
x_{t}+x_{t+1} \leq \omega_{t}^{i}, i=0,1 .
$$

Monotonicity of the utility function implies that his effective demand is $\widehat{x}_{t}^{d i}=\omega_{t}^{i}$.

Denote with $\lambda_{t}^{s}=\min \left\{L_{t}^{d} / L^{s}, 1\right\}$ the fraction of young consumers that will be employed, where $L_{t}^{d}$ denotes aggregate demand of labor and $L^{s}=n \ell^{s}$ aggregate supply. Then the aggregate demand of goods by young consumers in case of deflationary expectations $\theta_{t}^{e}<1$ is

$$
\begin{aligned}
X_{t}^{d} & \equiv \lambda_{t}^{s} n x_{t}^{d 1}+\left(1-\lambda_{t}^{s}\right) n x_{t}^{d 0} \\
& =h\left[(1-\operatorname{tax}) \frac{\Pi_{t-1}}{p_{t}}+\frac{w_{t}}{p_{t}} \lambda_{t}^{s} L^{s}\right] \\
& \equiv X^{d}\left(\lambda_{t}^{s} ; \frac{w_{t}}{p_{t}}, \frac{(1-\operatorname{tax}) \Pi_{t-1}}{p_{t}}, h\right)
\end{aligned}
$$

whereas in case of inflationary expectations $\theta_{t}^{e}>1$ it is

$$
\begin{aligned}
\widehat{X}_{t}^{d} & \equiv \lambda_{t}^{s} n \widehat{x}_{t}^{d 1}+\left(1-\lambda_{t}^{s}\right) n \widehat{x}_{t}^{d 0} \\
& =(1-\operatorname{tax}) \frac{\Pi_{t-1}}{p_{t}}+\frac{w_{t}}{p_{t}} \lambda_{t}^{s} L^{s} \\
& =X^{d}\left(\lambda_{t}^{s} ; \frac{w_{t}}{p_{t}}, \frac{(1-\operatorname{tax}) \Pi_{t-1}}{p_{t}}, 1\right) .
\end{aligned}
$$

From (1) and (2) it is evident that the only difference in the aggregate effective demand by young consumers implied by different

\footnotetext{
${ }^{11}$ Note that the function to be maximized is of the Cobb-Douglas type for which it is standard to see that it yields the maximizer given in the text.
} 
expectations $\theta_{t}^{e}$ smaller or larger than 1 lies in the multiplicative factor $\tau \in\{h, 1\}$. We shall therefore identify the value of $\tau$ with the corresponding expectation type.

The total effective aggregate demand of the consumption sector is now obtained by adding old consumers' aggregate demand $m_{t}=$ $M_{t} / p_{t}$ and government demand $G$ :

$$
Y_{t}^{d} \equiv X^{d}\left(\lambda_{t}^{s} ; \alpha_{t},(1-\operatorname{tax}) \pi_{t}, \tau\right)+m_{t}+G,
$$

where $\alpha_{t} \equiv w_{t} / p_{t}$ and $\pi_{t} \equiv \Pi_{t-1} / p_{t}$.

\subsection{The Production Sector}

All firms are identical and produce according to the same production function $y_{t}^{p}=f\left(\ell_{t}\right)=a \ell_{t}^{b}, a, b>0$. Denoting with $s_{t}$ the inventories held at the beginning of period $t$, the total amount supplied by a firm is $y_{t}^{s}=y_{t}^{p}+s_{t}$. Firms too may be rationed both on the goods and on the labor market by means of rationing mechanisms similar to those assumed for the consumption sector. For the labor market we assume again 0-1 rationing and thus, letting $\ell_{t}^{d}$ be the single firm's effective demand of labor and denoting with $\lambda_{t}^{d} \in[0,1]$ the probability that the firm is not rationed on the labor market, it follows that $E \ell_{t}=\lambda_{t}^{d} \ell_{t}^{d}$. On the goods market the rationing rule is assumed to be

$$
c y_{t}=\left\{\begin{array}{c}
y_{t}^{s}, \text { with prob. } \sigma \gamma_{t}^{s} \\
d_{t} y_{t}^{s}, \text { with prob. } 1-\sigma \gamma_{t}^{s}
\end{array}\right.
$$

where $\sigma \in(0,1), \gamma_{t}^{s} \in[0,1], d_{t}=\left(\gamma_{t}^{s}-\sigma \gamma_{t}^{s}\right) /\left(1-\sigma \gamma_{t}^{s}\right)$, and $y_{t}^{s}=f\left(\ell_{t}^{d}\right)+s_{t}$ denotes the firm's effective supply. $\sigma$ is a fixed parameter of the mechanism, whereas $\lambda_{t}^{d}$ and $\gamma_{t}^{s}$ are perceived rationing coefficients taken as given by the firm the value of which will be determined in equilibrium. The definition of $d_{t}$ implies that $E y_{t}=\gamma_{t}^{s} y_{t}^{s}$, which is independent of $\sigma$.

Note that there is an upper bound on a firm's effective labor demand since the firm must be prepared to finance labor purchases even when rationed on the goods market (the labor market is in 
fact visited first, so that rationing on the goods market is observed only after labor has been hired). Formally:

$$
0 \leq \ell_{t}^{d} \leq \frac{d_{t}}{\alpha_{t}}\left[f\left(\ell_{t}^{d}\right)+s_{t}\right]
$$

Each firm's effective labor demand $\ell_{t}^{d}=\ell^{d}\left(\gamma_{t}^{s} ; \alpha_{t}\right)$ is obtained by maximizing expected profits, $\gamma_{t}^{s}\left[f\left(\ell_{t}^{d}\right)+s_{t}\right]-\alpha_{t} \ell_{t}^{d}$, subject to (3). In general, the solution to this problem depends on the constraint (3), but the latter is not binding if $b \leq 1-\sigma$ (see Appendix 1, Lemma A.1). Under this assumption, we obtain

$$
\ell_{t}^{d}=\ell^{d}\left(\gamma_{t}^{s} ; \alpha_{t}\right)=\left(\frac{\gamma_{t}^{s} a b}{\alpha_{t}}\right)^{\frac{1}{1-b}} .
$$

Notice that labor demand is independent of $s_{t}$ because the latter enters in an additive way into the firm's objective function. This does not mean that $s_{t}$ is irrelevant; rather, as will be seen, the aggregate value of inventories, $S_{t}$, influences the firm's decision in an indirect way by affecting the (equilibrium) value of the rationing coefficient $\gamma_{t}^{s}$. The aggregate labor demand then is $L_{t}^{d}=n^{\prime} \ell^{d}\left(\gamma_{t}^{s} ; \alpha_{t}\right) \equiv L^{d}\left(\gamma_{t}^{s} ; \alpha_{t}\right)$ and, because only a fraction $\lambda_{t}^{d}$ of firms can hire workers, the aggregate supply of goods is

$$
Y_{t}^{s}=\lambda_{t}^{d} n^{\prime} f\left(\ell^{d}\left(\gamma_{t}^{s} ; \alpha_{t}\right)\right)+S_{t} \equiv Y^{s}\left(\lambda_{t}^{d}, \gamma_{t}^{s} ; \alpha_{t}, S_{t}\right)
$$

\section{Temporary Equilibrium Allocations}

For any $t$, a temporary equilibrium with rationing is described by the following

Definition 1. Given a real wage $\alpha_{t}$, a real profit level $\pi_{t}$, real money balances $m_{t}$, inventories $S_{t}$, a level of public expenditure $G$, a tax rate tax and an expectation type $\tau \in\{h, 1\}$, a list of rationing coefficients $\left(\gamma_{t}^{d}, \gamma_{t}^{s}, \lambda_{t}^{d}, \lambda_{t}^{s}, \delta_{t}, \varepsilon_{t}\right) \in[0,1]^{6}$ and an aggregate allocation $\left(\bar{L}_{t}, \bar{Y}_{t}\right)$ constitute a temporary equilibrium if the following conditions are fulfilled: 


$$
\begin{array}{ll}
\text { (C1) } & \bar{L}_{t}=\lambda_{t}^{s} L^{s}=\lambda_{t}^{d} L^{d}\left(\gamma_{t}^{s} ; \alpha_{t}\right) \\
\text { (C2) } & \bar{Y}_{t}=\gamma_{t}^{s} Y^{s}\left(\lambda_{t}^{d}, \gamma_{t}^{s} ; \alpha_{t}, S_{t}\right) \\
& =\gamma_{t}^{d} X^{d}\left(\lambda_{t}^{s} ; \alpha_{t},(1-\operatorname{tax}) \pi_{t}, \tau\right)+\delta_{t} m_{t}+\varepsilon_{t} G ; \\
\text { (C3) } & \left(1-\lambda_{t}^{s}\right)\left(1-\lambda_{t}^{d}\right)=0 ;\left(1-\gamma_{t}^{s}\right)\left(1-\gamma_{t}^{d}\right)=0 ; \\
\text { (C4) } & \gamma_{t}^{d}\left(1-\delta_{t}\right)=0 ; \delta_{t}\left(1-\varepsilon_{t}\right)=0 .
\end{array}
$$

Conditions ( $\mathrm{C} 1)$ and $(\mathrm{C} 2)$ require that agents correctly perceive the rationing coefficients $\gamma_{t}^{d}, \gamma_{t}^{s}, \lambda_{t}^{d}$ and $\lambda_{t}^{s}$ so that the expected aggregate transactions balance. In addition, condition (C3) formalizes the short-side rule guaranteeing that at most one side on each market is rationed. Finally, since also old households and/or the government can be rationed (with rationing coefficients $\delta_{t}$ and $\left.\varepsilon_{t}\right)$, conditions $(\mathrm{C} 2)$ and $(\mathrm{C} 4)$ take care of this but require it to happen only after young households have been rationed to zero. Furthermore, the government can be rationed only if both young and old consumers are rationed to zero.

Definition 1 allows to distinguish different types of equilibrium according to which market sides are rationed: excess supply on both markets $\left(\lambda_{t}^{s}<1, \gamma_{t}^{s}<1\right)$ is called Keynesian Unemployment $[K]$, excess demand on both markets $\left(\lambda_{t}^{d}<1, \gamma_{t}^{s}<1\right)$ Repressed Inflation $[I]$, excess supply on the labor market $\left(\lambda_{t}^{s}<1\right)$ and excess demand on the goods market $\left(\gamma_{t}^{d}<1\right)$ Classical Unemployment $[C]$, and excess demand on the labor market $\left(\lambda_{t}^{d}<1\right)$ with excess supply on the goods market $\left(\gamma_{t}^{d}<1\right)$ Underconsumption $[U]$. Of course, there are further intermediate cases which, however, can be considered as limiting cases of the above ones. In particular, when all the rationing coefficients are equal to one, we are in a Walrasian Equilibrium.

The following proposition establishes the existence and uniqueness of temporary equilibrium.

Proposition 1. For any list of variables $\left(\alpha_{t}, m_{t}, \pi_{t}, S_{t}\right)$, with $\alpha_{t}$ strictly positive and $m_{t}, \pi_{t}$ and $S_{t}$ non-negative, any non-negative pair of policy parameters $(G, \operatorname{tax})$ and any expectation type $\tau \in$ $\{h, 1\}$, there exists a unique temporary equilibrium allocation $\left(\bar{L}_{t}, \bar{Y}_{t}\right)$. 
$\bar{L}_{t}$ is given by

$$
\begin{aligned}
\bar{L}_{t} & =\min \left\{\widetilde{L}\left(\alpha_{t}, \pi_{t}, m_{t}, S_{t}, G, \operatorname{tax}, \tau\right), L^{d}\left(1, \alpha_{t}\right), L^{s}\right\} \\
& \equiv \mathcal{L}\left(\alpha_{t}, \pi_{t}, m_{t}, S_{t}, G, \operatorname{tax}, \tau\right)
\end{aligned}
$$

where $\widetilde{L}\left(\alpha_{t}, \pi_{t}, m_{t}, S_{t}, G, \operatorname{tax}, \tau\right)$ is the unique solution in $L$ of

$$
\alpha_{t}\left(\frac{1}{b}-\tau\right) L+\frac{\alpha_{t}}{a b}\left(\frac{L}{n^{\prime}}\right)^{1-b} S_{t}=\tau(1-\operatorname{tax}) \pi_{t}+m_{t}+G
$$

and

$$
L^{d}\left(1, \alpha_{t}\right)=n^{\prime}\left(\frac{a b}{\alpha_{t}}\right)^{\frac{1}{1-b}} .
$$

$\bar{Y}_{t} \equiv \mathcal{Y}\left(\alpha_{t}, \pi_{t}, m_{t}, S_{t}, G\right.$, tax,$\left.\tau\right)$ is determined as follows. If $\bar{L}_{t}=$ $\widetilde{L}(\cdot)$, then $\bar{Y}_{t}=\frac{\alpha_{t}}{b} \bar{L}_{t}+\frac{\alpha_{t}}{a b}\left(\frac{\bar{L}_{t}}{n^{\prime}}\right)^{1-b} S_{t}$, and if $\bar{L}_{t}=L^{d}\left(1, \alpha_{t}\right)$, then $\bar{Y}_{t}=\frac{\alpha_{t}}{b} L^{d}\left(1, \alpha_{t}\right)+S_{t}$. Finally, if $\bar{L}_{t}=L^{s}$, then $\bar{Y}_{t}=$ $\min \left\{\frac{\alpha_{t}}{b} L^{s}+S_{t}, \tau(1-\operatorname{tax}) \pi_{t}+\tau \alpha_{t} L^{s}+m_{t}+G\right\}$.

Proof. See Appendix 1.

For the sake of illustration, let us consider a situation of Keynesian Unemployment in which $\tau=h$. This type of equilibrium involves rationing of households on the labor market and of firms on the goods market. It is given by a pair $\left(\lambda_{t}^{s}, \gamma_{t}^{s}\right)$ such that

$$
\begin{aligned}
\bar{L}_{t} & =\lambda_{t}^{s} L^{s}=L^{d}\left(\gamma_{t}^{s}\right) \\
\bar{Y}_{t} & =\gamma_{t}^{s} Y^{s}\left(1, \gamma_{t}^{s}\right)=X^{d}\left(\lambda_{t}^{s}\right)+m_{t}+G
\end{aligned}
$$

where we have suppressed all arguments that are not rationing coefficients.

The consumption sector supplies the amount of labor $L^{s}>\bar{L}_{t}$ and demands the quantity of goods $Y_{t}^{d}=\bar{Y}_{t}$, whereas firms demand labor $L_{t}^{d}=\bar{L}_{t}$ and supply $Y_{t}^{s}>\bar{Y}_{t}$ of goods. It follows that $\lambda_{t}^{s}=\bar{L}_{t} / L^{s}, \gamma_{t}^{s}=\bar{Y}_{t} / Y_{t}^{s}$ and $\lambda_{t}^{d}=\gamma_{t}^{d}=1\left(=\delta_{t}=\varepsilon_{t}\right)$, which are just the values that lead households and firms to express their respective transaction offers. Thus their expectations 
regarding these rationing coefficients are confirmed. Nevertheless, due to the randomness in rationing at an individual agent's level, effective aggregate demands and supplies of rationed agents exceed their actual transactions. Moreover, as indicated earlier, these excesses can be used to get an indicator of the strength of rationing. Since there is zero-one rationing on the labor market, $1-\lambda_{t}^{s}=\left(L^{s}-\bar{L}_{t}\right) / L^{s}$ is the unemployment rate. On the goods market, in a $K$-equilibrium we have $\bar{Y}_{t}-\gamma_{t}^{s} Y^{s}\left(1, \gamma_{t}^{s}\right)=0$ and, since $\partial Y^{s} / \partial \gamma_{t}^{s}=n^{\prime} f^{\prime}\left(\ell^{d}\left(\gamma_{t}^{s}\right)\right) \frac{d \ell^{d}}{d \gamma_{t}^{s}}>0$, a decrease in $\bar{Y}_{t}$, for example due to a reduction in government spending, implies a decrease in $\gamma_{t}^{s}$, i.e. an increase in $1-\gamma_{t}^{s}$. Thus, an aggravation of the shortage of aggregate demand for firms' goods is unambiguously related to an increase in $1-\gamma_{t}^{s}$ which can therefore be interpreted as a measure of the strength of rationing on the goods market. A similar reasoning justifies the use as rationing measures of the terms $1-\lambda_{t}^{d}$ and $1-\gamma_{t}^{d}$ in the other equilibrium regimes.

\section{Dynamics}

The link between successive periods is given by the adjustment of prices, by the changes in the stock of money and in profits, and by possible changes in the expectation type. The latter is a somewhat subtle issue that we will treat as the last point in our description of the dynamics. Initially, we assume a given expectation type $\tau \in\{h, 1\}$ and proceed as if this type were constant. Later we will introduce the possibility of expectation switching.

For given $\tau$, the adjustment of prices and wages is such that the price rises (falls) whenever an excess of demand (supply) is observed. Hence, in terms of the rationing coefficients observed in period $t$, we have that

$$
\begin{gathered}
p_{t+1}<p_{t} \Leftrightarrow \gamma_{t}^{s}<1, p_{t+1}>p_{t} \Leftrightarrow \gamma_{t}^{d}<1, \\
w_{t+1}<w_{t} \Leftrightarrow \lambda_{t}^{s}<1, w_{t+1}>w_{t} \Leftrightarrow \lambda_{t}^{d}<1 .
\end{gathered}
$$


More precisely, our simulations are based on the following adjustment mechanisms:

$$
\begin{gathered}
p_{t+1}= \begin{cases}{\left[1-\mu_{1}\left(1-\gamma_{t}^{s}\right)\right] p_{t}} & \text { if } \gamma_{t}^{s} \leq 1 \\
{\left[1+\mu_{2}\left(1-\frac{\gamma_{t}^{d}+\delta_{t}+\varepsilon_{t}}{3}\right)\right] p_{t}} & \text { if } \gamma_{t}^{d} \leq 1\end{cases} \\
w_{t+1}= \begin{cases}{\left[1-\nu_{1}\left(1-\lambda_{t}^{s}\right)\right] w_{t}} & \text { if } \lambda_{t}^{s} \leq 1 \\
{\left[1+\nu_{2}\left(1-\lambda_{t}^{d}\right)\right] w_{t}} & \text { if } \lambda_{t}^{d} \leq 1\end{cases}
\end{gathered}
$$

where $\mu_{1}, \mu_{2}, \nu_{1}, \nu_{2} \in[0,1]$ can be interpreted as the degree of flexibility of adjustment. The dynamics of the real wage is then described by the following equations:

$$
\alpha_{t+1}=\left\{\begin{array}{cc}
\frac{1-\nu_{1}\left(1-\lambda_{t}^{s}\right)}{1-\mu_{1}\left(1-\gamma_{t}^{s}\right)} \alpha_{t} & \text { if }\left(\bar{L}_{t}, \bar{Y}_{t}\right) \in K \\
\frac{1-\nu_{1}\left(1-\lambda_{t}^{s}\right)}{1+\mu_{2}\left(1-\frac{\gamma_{t}^{d}+\delta_{t}+\varepsilon_{t}}{3}\right)} \alpha_{t} & \text { if }\left(\bar{L}_{t}, \bar{Y}_{t}\right) \in C \\
\frac{1+\nu_{2}\left(1-\lambda_{t}^{d}\right)}{1+\mu_{2}\left(1-\frac{\gamma_{t}^{d}+\delta_{t}+\varepsilon_{t}}{3}\right)} \alpha_{t} & \text { if }\left(\bar{L}_{t}, \bar{Y}_{t}\right) \in I \\
\frac{1+\nu_{2}\left(1-\lambda_{t}^{d}\right)}{1-\mu_{1}\left(1-\gamma_{t}^{s}\right)} \alpha_{t} & \text { if }\left(\bar{L}_{t}, \bar{Y}_{t}\right) \in U
\end{array}\right.
$$

whereas the inflation factor $\theta_{t}=p_{t+1} / p_{t}$ is given by

$$
\theta_{t}=\left\{\begin{array}{ll}
1-\mu_{1}\left(1-\gamma_{t}^{s}\right) & \text { if }\left(\bar{L}_{t}, \bar{Y}_{t}\right) \in K \cup U \\
1+\mu_{2}\left(1-\frac{\gamma_{t}^{d}+\delta_{t}+\varepsilon_{t}}{3}\right) & \text { if }\left(\bar{L}_{t}, \bar{Y}_{t}\right) \in C \cup I
\end{array} .\right.
$$

The dynamics of profits, money and inventories follow from the definition of these variables and equations (5)-(8) and (11)-(12), i.e.

$$
\pi_{t+1}=\frac{\bar{Y}_{t}-\alpha_{t} \bar{L}_{t}}{\theta_{t}},
$$




$$
\begin{aligned}
m_{t+1} & =\frac{M_{t+1}}{p_{t+1}} \\
& =\frac{1}{p_{t+1}}\left[(1-\operatorname{tax}) \Pi_{t-1}+w_{t} \bar{L}_{t}-p_{t} \bar{Y}_{t}+\delta_{t} M_{t}+\varepsilon_{t} p_{t} G\right] \\
& =\frac{1}{\theta_{t}}\left[(1-\operatorname{tax}) \pi_{t}+\alpha_{t} \bar{L}_{t}-\bar{Y}_{t}+\delta_{t} m_{t}+\varepsilon_{t} G\right] \\
& =\frac{1}{\theta_{t}}\left[\delta_{t} m_{t}+\varepsilon_{t} G+(1-\operatorname{tax}) \pi_{t}\right]-\pi_{t+1}
\end{aligned}
$$

and

$$
S_{t+1}=Y^{s}\left(\lambda_{t}^{d}, \gamma_{t}^{s} ; \alpha_{t}, S_{t}\right)-\bar{Y}_{t}=\lambda_{t}^{d} n^{\prime} a\left(\frac{\gamma_{t}^{s} a b}{\alpha_{t}}\right)^{\frac{b}{1-b}}+S_{t}-\bar{Y}_{t},
$$

where

$\bar{Y}_{t}=\mathcal{Y}\left(\alpha_{t}, \pi_{t}, m_{t}, S_{t}, G, \operatorname{tax}, \tau\right)$ and $\bar{L}_{t}=\mathcal{L}\left(\alpha_{t}, \pi_{t}, m_{t}, S_{t}, G, \operatorname{tax}, \tau\right)$

It then follows that the dynamics of the model is given by the sequence $\left\{\left(\alpha_{t}, m_{t}, \pi_{t}, S_{t}\right)\right\}_{t=1}^{\infty}$. The values of the rationing coefficients $\left(\gamma_{t}^{d}, \gamma_{t}^{s}, \lambda_{t}^{d}, \lambda_{t}^{s}, \delta_{t}, \varepsilon_{t}\right)$ are determined in Appendix 2 where the corresponding explicit equations of the complete dynamic system are also stated.

We introduce now the possibility of expectation switching. We would like this to occur whenever it is required in order to keep expectations correct along a trajectory of the system. ${ }^{12}$ For example, consider the case that, in period $t$, consumers have deflationary expectations $\left(\theta_{t}^{e} \leq 1\right.$ or, equivalently, $\tau=h$ ) but the equilibrium in period $t$ is such that there is excess demand on the goods market and thus $p_{t+1}>p_{t}$. Then the assumption $\tau=h$ in period $t$ has been incorrect and we substitute it by $\tau=1$, i.e. $\theta_{t}^{e}>1$. Of course then a different equilibrium arises in period $t$ but we claim that the type of equilibrium is still such that there is excess demand on

${ }^{12}$ Although we are not going to model the process of how expectations are effectively generated, we can think of a scenario in which a central forecasting institute be able to predict correctly whether in the next period there will be inflation or deflation. 
the goods market. Therefore expectations have been adjusted so as to become correct. Analogously we correct the expectations in case $\theta_{t}^{e}>1$ but the equilibrium in period $t$ involves excess supply on the goods market. The rationale for doing this is given by the following

Lemma 1. Assume that for $\tau=h$ in period $t$ an equilibrium with $\gamma_{t}^{d}<1$ occurs. Then this inequality is preserved when switching in period $t$ to $\tau=1$. Conversely, assume that for $\tau=1$ in period $t$ an equilibrium with $\gamma_{t}^{s}<1$ occurs. Then this inequality is preserved when switching in period t to $\tau=h$.

Proof: Assume that $\tau=h$ in period $t$ and that in the corresponding equilibrium we have $\gamma_{t}^{d}<1$. Then there is excess demand on the goods market, i.e. $Y_{t}^{d}=X_{t}^{d}+m_{t}+G>Y_{t}^{s}$. If $\tau$ is changed to $\tau=1$, then by (1) and (2) $X_{t}^{d}$ increases. Thus the excess of demand over supply on the goods market can only increase and in particular $Y_{t}^{d}>Y_{t}^{s}$ still holds.

Conversely, consider $\tau=1$ in period $t$ and $\gamma_{t}^{s}<1$. Then $Y_{t}^{d}<Y_{t}^{s}$ and changing $\tau$ from 1 to $h$ decreases $X_{t}^{d}$, thus $Y_{t}^{d}$, and $Y_{t}^{d}<Y_{t}^{s}$ is preserved.

Taking into account expectations switching, a trajectory of the dynamic system is now given by a sequence $\left\{\left(\alpha_{t}, m_{t}, \pi_{t}, S_{t}, \tau_{t}\right)\right\}_{t=1}^{\infty}$. Note that these state variables are perfectly foreseen by economic agents in any period $t$. This is a remarkable property of the model as the dynamic system it gives rise to is a truly forward looking one. ${ }^{13}$

\footnotetext{
${ }^{13}$ In most cases of dynamic systems in economics, they are given by a system of implicit difference equations, in which case an explicit solution in the sense of a (local) flow of mappings cannot be computed analytically; see e.g. Grandmont (1985), Grandmont and Laroque (1986), or Chiappori and Guesnerie (1991). On the other hand, models that avoid this problem - giving rise to truly forward looking dynamic systems - typically are not compatible with perfect foresight outside the stationary state. For a systematic discussion of this issue see e.g. Böhm and Wenzelburger (1999).
} 


\section{Simulations}

The non-linear dynamic system describing our economy is fivedimensional, with state variables $\alpha_{t}, m_{t}, \pi_{t}, S_{t}$ and $\tau_{t}$. Moreover, since there are four equilibrium regimes, it can be viewed as being composed of four subsystems each of which may become effective through endogenous regime switching. It is therefore necessary to resort to numerical simulations in order to study the dynamics of our economy. ${ }^{14}$

The basic parameter set specifies values for the technological coefficients ( $a$ and $b$ ), the exponent of the utility function $(h)$, the labor supply $\left(L^{s}\right)$ and the total number of producers in the economy $\left(n^{\prime}\right)$, the price adjustment speeds downward and upward (respectively $\mu_{1}$ and $\mu_{2}$ ), and the corresponding wage adjustment speeds $\left(\nu_{1}\right.$ and $\left.\nu_{2}\right)$. It further assumes initial values for the state variables $\left(\alpha_{0}, m_{0}, \pi_{0}, S_{0}\right.$ and $\left.\tau_{0}\right)$ and for the price level $\left(p_{0}\right)$, and values for the government policy parameters $(G$ and tax). Having chosen $p_{0}$, the goods price level $p_{t}$ for any $t$ - and consequently $w_{t}=\alpha_{t} p_{t}$ and $M_{t}=m_{t} p_{t}$ - is determined by means of (9).

Letting $a=1, b=0.85, h=0.5, L^{s}=100$ and $n^{\prime}=100$, a stationary Walrasian equilibrium is obtained for

$$
\begin{aligned}
& \alpha^{*}=0.85, \quad m^{*}=46.25, \quad \pi^{*}=15, \quad S^{*}=0, \\
& G^{*}=7.5, \quad \text { tax }^{*}=0.5, \quad \tau^{*}=h,
\end{aligned}
$$

with trading levels $L^{*}=Y^{*}=100 .^{15}$ Out of Walrasian equilibrium we will vary the downward (upward) adjustment speeds of wages $\nu_{1}\left(\nu_{2}\right)$, while we will stick to $\mu_{1}=\mu_{2}=0.1$ for the adjustment speeds of prices.

In our numerical simulations we will focus on the consequences of a restrictive monetary shock determining a reduction in the ini-

\footnotetext{
${ }^{14}$ Our numerical simulations are based on the package MACRODYN that has been developed by Volker Böhm at the University of Bielefeld.

${ }^{15}$ Note that there is a second Walrasian equilibrium in which $\tau^{*}=1, m^{*}=0$ and all other values are those given in (13). That equilibrium is equivalent to the one with $\tau^{*}=h$ and $m^{*}=46.25$ in the sense that both equilibria give rise to the same utility of consumers (46.25).
} 
tial money stock to $m_{0}=40$, keeping all other parameters and initial values at their Walrasian levels. ${ }^{16}$ Since $m_{0}$ is the demand of old agents at time $t=0$, aggregate demand is reduced, which implies excess supply on the goods market (and a reduction in the goods price). As a consequence, firms reduce their labor demand, which in turn implies excess supply also on the labor market, and the economy enters in a state of Keynesian unemployment. If the wage rate falls more than the goods price, the real wage decreases, and it may converge to a limit level below the Walrasian real wage. A lower real wage determines a reduction in the labor income of workers and therefore in the aggregate goods demand, keeping employment below full employment. In this case, the restrictive monetary shock causes a permanent decrease in employment and output. Due to the falling government spending in nominal terms, the government is permanently realizing a budget surplus (i.e. $\left.\Delta M=p_{t} G-\operatorname{tax} \Pi_{t-1}<0\right)$ and therefore the nominal money stock shrinks. Figure 1, which shows time series for $\nu_{1}=0.025$ and $\nu_{2}=0.1$, illustrates the convergence of the dynamic system to a quasi-stationary Keynesian state with permanent deflation of all nominal variables but constant real magnitudes. The restrictive monetary shock has caused a permanent decrease in employment and output.

\footnotetext{
${ }^{16}$ This monetary shock should be considered a proxy for a more realistic monetary policy.
} 

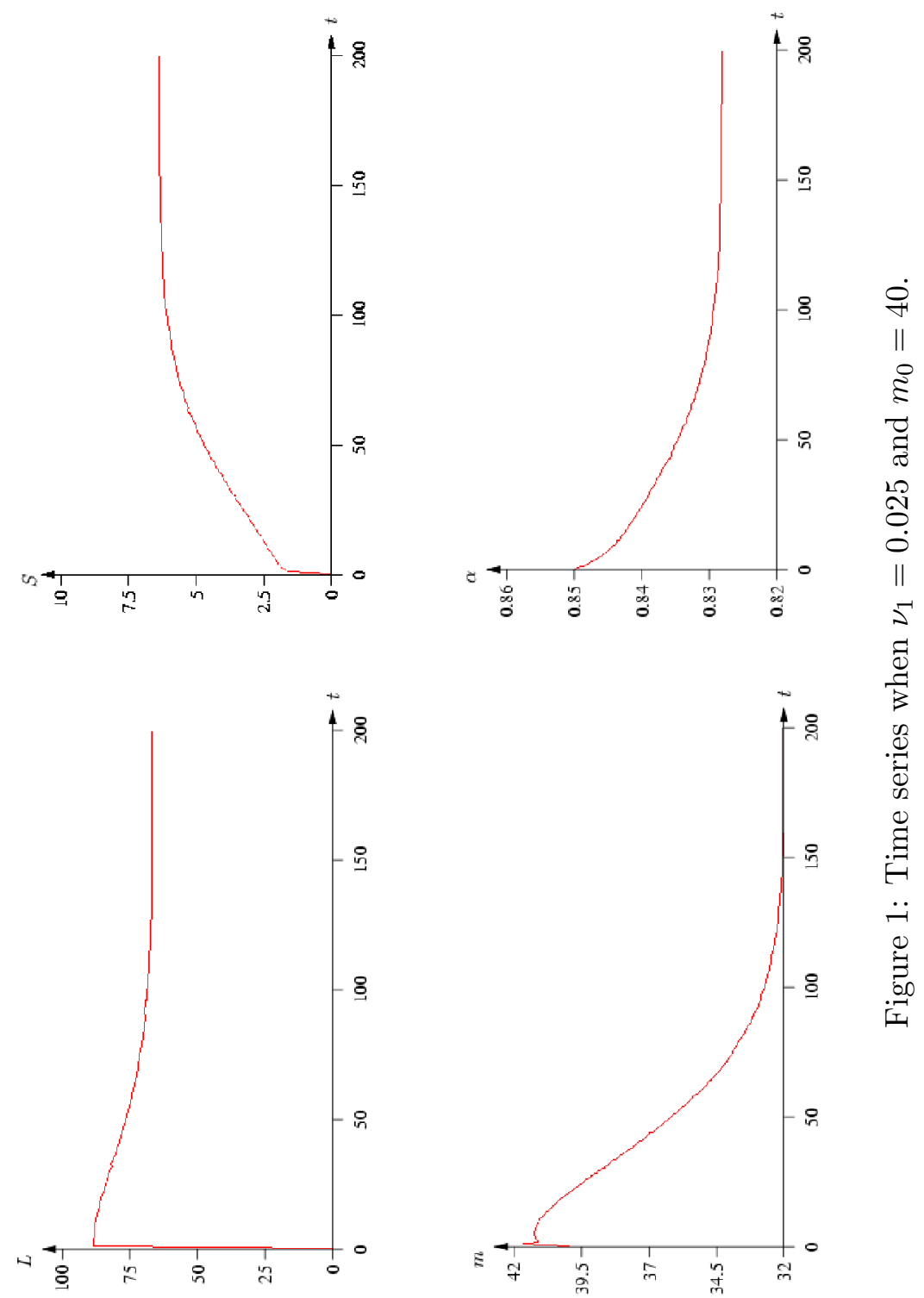
Inventories are decisive here as their presence amplifies the fall of labor demand by firms, further depressing real labor income and aggregate demand. In fact, when aggregate demand is diminished due to a decrease in $m_{0}$, inventories become positive and rise further as excess supply on the goods market builds up. As $\gamma^{s}=\bar{Y}_{t} / Y^{s}\left(\lambda_{t}^{d}, \gamma_{t}^{s} ; \alpha_{t}, S_{t}\right)$ by (C2) of Definition 1 and $S_{t}$ influences $Y^{s}$ positively by (5), an increase in $S_{t}$ reduces the sales expectation ratio $\gamma^{s}$ which by (4) diminishes the labor demand more than would be the case without inventories. ${ }^{17}$

Finally, it is natural to ask whether different degrees of downward wage flexibility give rise to convergence to a full employment equilibrium or, on the contrary, to an even deeper recession. It turns out that this depends indeed on that degree, as shown in the bifurcation diagram of Figure 2.

All other things equal, approximately until $\nu_{1}=0.018$ the economy returns to full employment after the monetary shock, whereas for speeds of wage adjustment larger than this it gets trapped in underemployment.

\section{$6 \quad$ Stability}

The fact that a restrictive monetary shock may lead to a quasistationary Keynesian Unemployment state as limit of the dynamic system's trajectory raises the wider question of the stability of such a state. Analogously, the stability of the stationary Walrasian equilibrium or of a possible quasi-stationary inflationary state may be investigated. ${ }^{18}$ To anticipate the answer, numeri-

\footnotetext{
${ }^{17}$ Indeed, when not allowing for inventories as in Colombo and Weinrich (2003) and in Bignami, Colombo and Weinrich (2004), the implications of a monetary shock change entirely, with the economy returning to the Walrasian equilibrium. The real wage decreases initially but then the decrease in the goods price dominates the one in the nominal wage, and the real wage moves back to its Walrasian level, as do all the other variables.

${ }^{18} \mathrm{It}$ is straightforward to see from equations (9) and (10) that there can never exist quasi-stationary states in the Classical Unemployment and the Underconsumption regimes.
} 


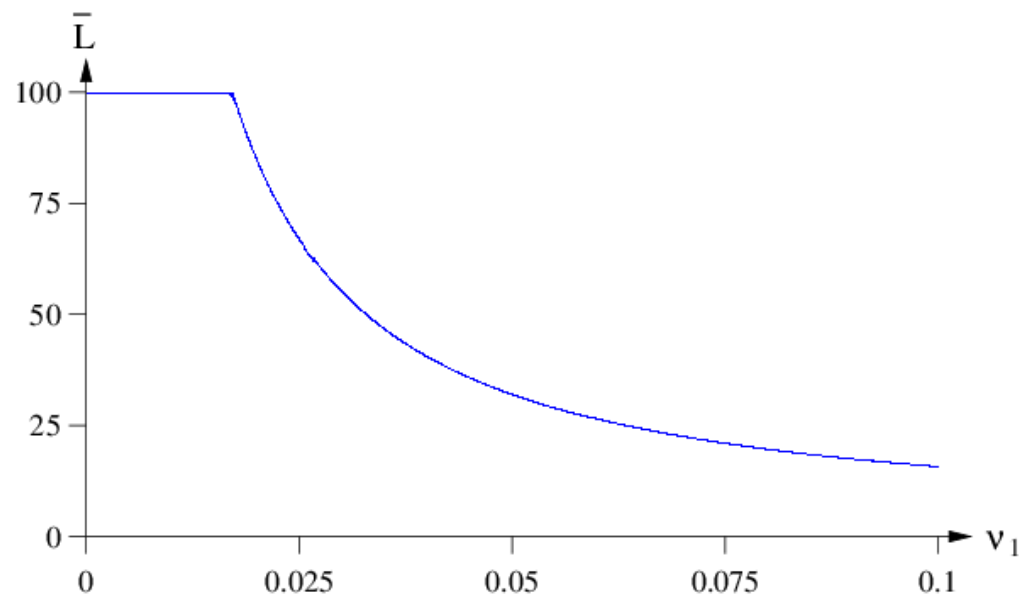

Figure 2: Stationary employment values when $m_{0}=40$.

cal simulations suggest that the Walrasian equilibrium is unstable whereas the Keynesian Unemployment state and the quasistationary Repressed Inflation state (the existence of which will be shown below) are locally stable.

Let us first look at the quasi-stationary Keynesian state. The limit values of the state variables of the simulation shown in Figure 1 , where we have an initial reduction of the money stock to $m_{0}=40$ at a downward wage flexibility of $\nu_{1}=0.025$ and policy parameters $G^{*}=7.5$ and $t a x^{*}=0.5$, are (approximately)

$$
\bar{\alpha}=0.8281, \quad \bar{m}=31.9263, \quad \bar{\pi}=15.7889, \quad \bar{S}=6.4060, \quad \bar{\tau}=0.5,
$$

with a stationary employment level $\bar{L}=66.9342$. We now take these stationary values as new initial values, i.e. set $\left(\alpha_{0}, m_{0}, \pi_{0}, S_{0}, \tau_{0}\right)$ $=(\bar{\alpha}, \bar{m}, \bar{\pi}, \bar{S}, \bar{\tau})$, and perform a bifurcation analysis with respect to each of the state variables around these initial values and dependent variable the employment level $\bar{L}$. The results are shown 
in Figure 3.

The diagrams show that local deviations in any of the state variables do not change the fact that the system has this state as an attracting long-run rest point. Although this is not a strict proof of local stability, it is highly indicative of the dynamic system's behavior. Moreover, in order to return from the stationary recessionary state to permanent full employment by changing only the money stock, an increase in that variable to its Walrasian value (46.25) is not sufficient, but a higher increase, to approximately 51 , would be needed. The case is still worse for a unilateral variation of real profits which would have to be more than tripled, to around 52, to get permanently out of unemployment. In both cases the reason is intuitively clear: only a substantial increase in the purchasing power of consumers, old or young, can succeed to change the situation of insufficient aggregate demand causing Keynesian Unemployment. A detailed analysis of the respective time series shows that, after an initial shock to $m_{0}>51$ or $\pi_{0}>52$, the system enters in the regime of Repressed Inflation where it converges to a full employment state which, as will be shown below, will be quasi-stationary.

The panel of Figure 3 showing the bifurcation diagram over inventories indicates that no change in the initial value of $S$ is by itself sufficient to overcome the recessionary state. Even a temporary decrease of inventories to zero is not capable to lead the dynamic system out of the Keynesian Unemployment regime because the insufficient demand quickly builds up inventories again and restores the old situation. 

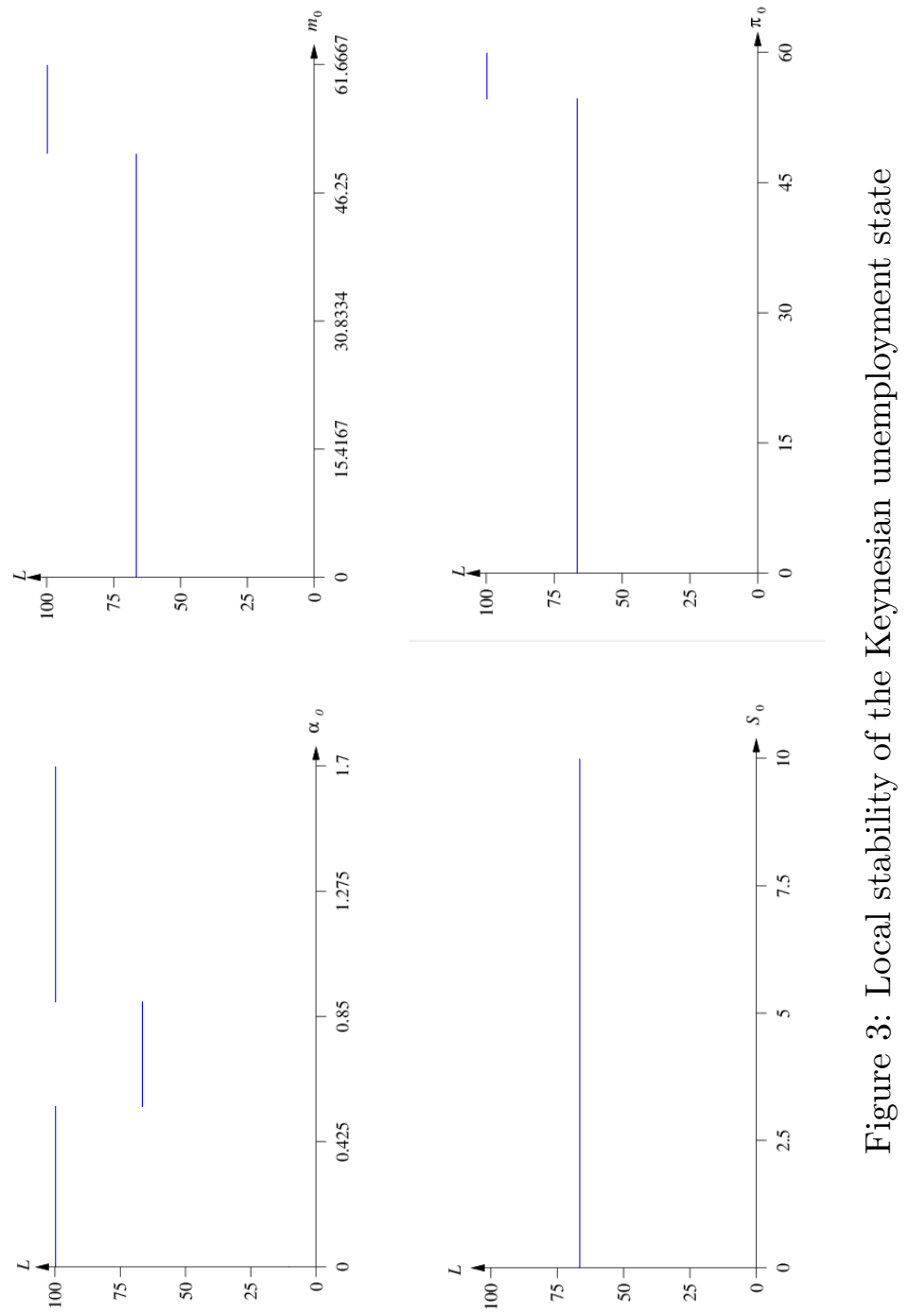
A less immediate intuition is available for the effects of a change in the initial value of the real wage $\alpha$. An increase of its value from the stationary state value typically results in a state of Classical Unemployment, because the high real wage not only creates excess demand on the goods market but also excess supply on the labor market. This implies a decrease in the nominal wage, an increase in the goods price and a decrease in the real wage. On the one hand, this decreases the income of employed workers, on the other hand it increases labor demand and thus the number of employed workers. Hence from Classical unemployment the economy may move to Keynesian Unemployment or to Repressed Inflation. What it does depends on how large the initial increase in the real wage is. If it is not very large ( $\alpha_{0}$ less than 0.901), the first of the above effects prevails and the system returns into the Keynesian regime. There inventories are built up and the system converges to the quasi-stationary Keynesian state. Conversely, if the initial increase in the real wage was large enough $\left(\alpha_{0}>0.901\right)$, it is the second effect that prevails - aggregate demand increases - and the economy enters into the inflationary regime where it converges to an inflationary quasi-stationary state. On the other hand, a decrease of $\alpha_{0}$ from $\bar{\alpha}$ typically leads the dynamic system to enter into the regime of Repressed Inflation. From there it may return to the Keynesian regime (for values of $\alpha_{0}$ above 0.547 ) or overshoot and converge to an inflationary state (for $\alpha_{0}$ smaller than 0.547), which is characterized below. ${ }^{19}$

Let us now look at the Walrasian stationary equilibrium given by the values in (13). Setting $\left(\alpha_{0}, m_{0}, \pi_{0}, S_{0}, \tau_{0}\right)=\left(\alpha^{*}, m^{*}, \pi^{*}, S^{*}, \tau^{*}\right)$ and performing bifurcation analyses analogous to the ones done above yields Figure 4. From this it can be seen that the Walrasian state is unstable in three of the four directions defined by the state variables, namely $m, \pi$ and $S$. Only in direction $\alpha$ is the system

\footnotetext{
${ }^{19}$ Note that a variation of $\tau$ from $h$ to 1 would not be a local variation because any local variation is characterized by $\tau \in(h-\varepsilon, h+\varepsilon) \cap D_{\tau}$ for some $\varepsilon>0$, where $D_{\tau}$ denotes the domain of $\tau$. But $(h-\varepsilon, h+\varepsilon) \cap D_{\tau}=\{h\}$, and thus the system is (trivially) locally stable with respect to $\tau$.
} 
locally stable. Whenever $m_{0}<m^{*}, \pi_{0}<\pi^{*}$ or $S_{0}>S^{*}$, the dynamic system diverges from the Walrasian state and converges to the quasi-stationary Keynesian unemployment state considered above with $\bar{L}=66.9342$. Thus the Walrasian equilibrium is locally unstable. ${ }^{20}$

Finally, by proceeding in an analogous way as for the Keynesian regime, but assuming an expansionary monetary shock, we can characterize a quasi-stationary Repressed Inflation state by the following values of the state variables:

$$
\bar{\alpha}=0.8482, \quad \bar{m}=3.8432, \quad \bar{\pi}=14.9478, \quad \bar{S}=0, \quad \bar{\tau}=1,
$$

with a stationary inflation rate $\phi_{t}=0.138992$, where $\phi_{t}$ is defined as the percentage price inflation $\phi_{t}=100\left(p_{t+1}-p_{t}\right) / p_{t}$. Taking as before these values as the initial ones, Figure 5 shows bifurcation analyses with respect to each of the state variables around them. From these it appears that this state is locally stable. ${ }^{21}$ Note that the above results are obtained for specific parameter values. One particularly significant parameter here is the downward wage flexibility $\nu_{1}$. In the present simulations this value has been set to 0.025 , but similar results hold whenever $\nu_{1}$ is above the benchmark value seen in Figure 2 (approximately 0.018) that separates the stationary values of employment from full to below full employment.

\footnotetext{
${ }^{20}$ Note that the fact that the Walrasian equilibrium is locally unstable does not mean that there does not exist a subset of the parameter set such that, starting from a point in that subset, the dynamic system converges to it.

${ }^{21}$ Observe that the above stationary values are very close to those corresponding to the Walrasian equilibrium with $\tau^{*}=1$ indicated in Footnote 11 . Moreover, it can be shown that consumers' utility in this inflationary state is the same as that in the Walrasian equilibrium (46.25) while the utility corresponding to the quasi-stationary Keynesian equilibrium is significantly smaller (31.66).
} 

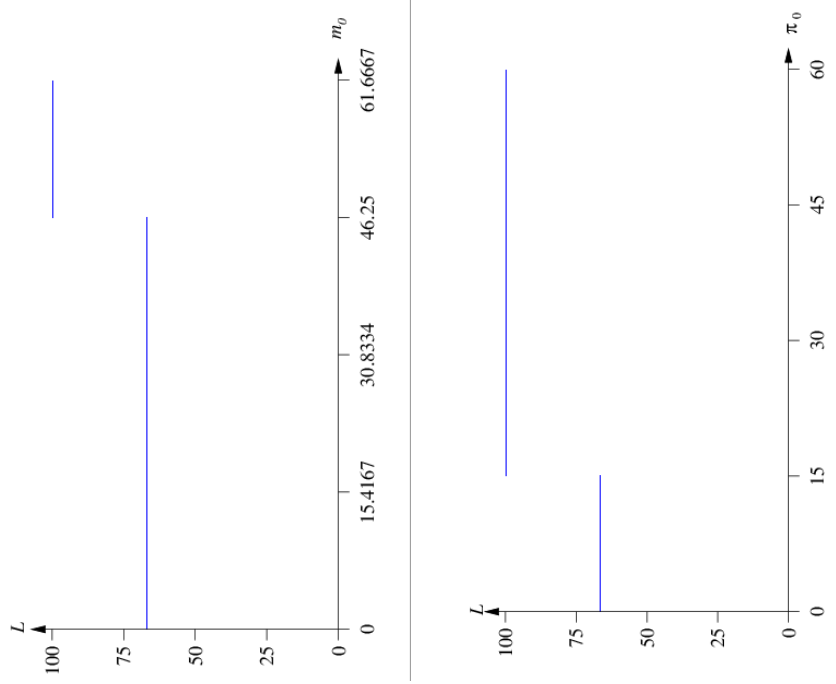

हే
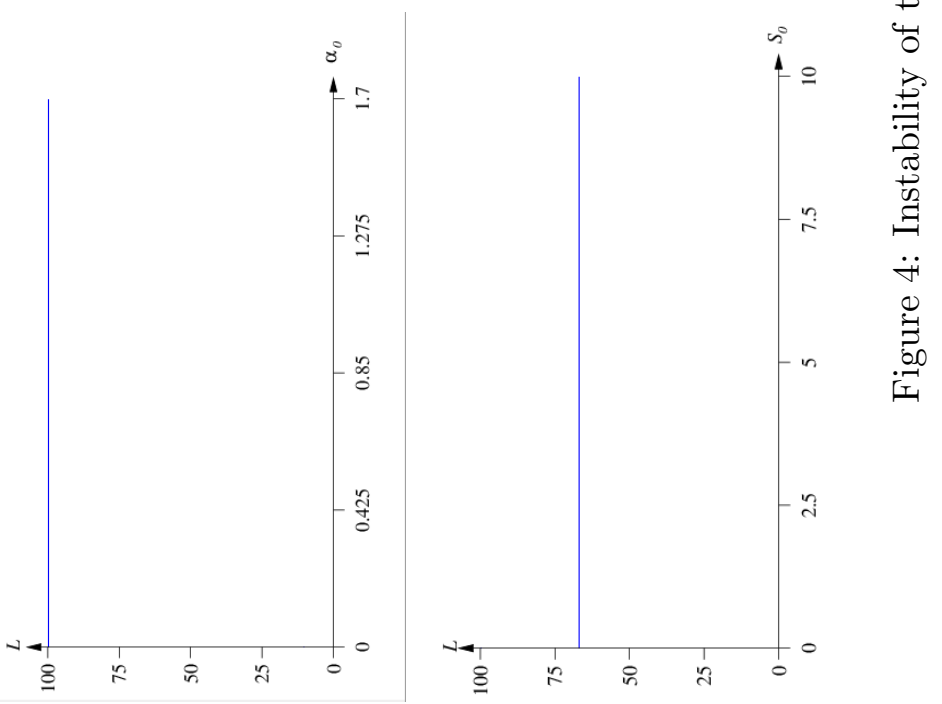

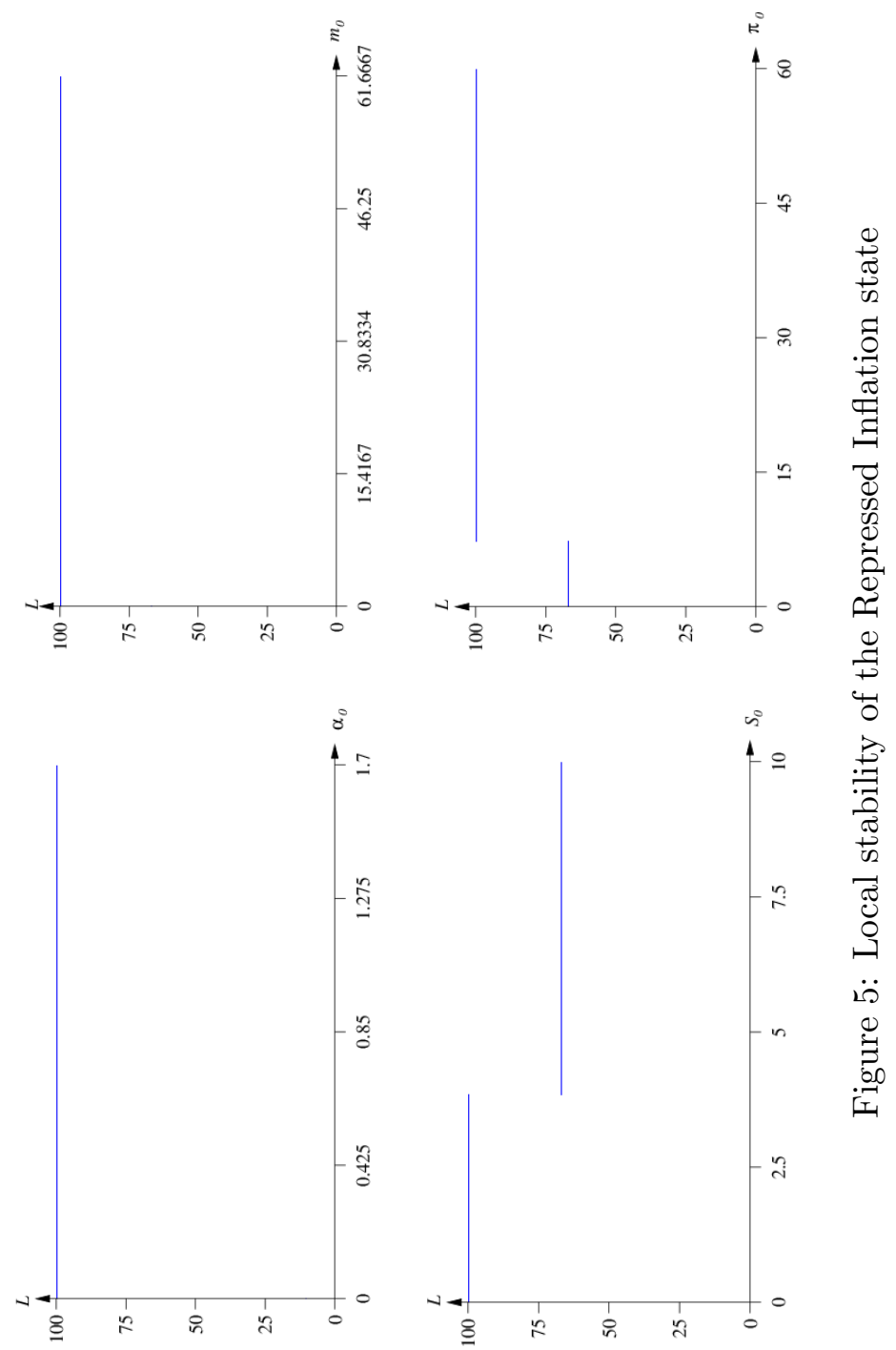


\section{Policy}

When an economy is stuck in a deflationary recession, a natural question to ask is how to get out of it. That this is not automatic has been put in evidence at least twice, during the Great Depression and more recently in the case of the Japanese economy. Its performance since the early 1990s with prolonged recession, unemployment, overcapacity/excess inventories and falling prices and nominal wages fits into our scenario of a quasi-stationary state with Keynesian unemployment. Thus, we are challenged to apply the insights from our theoretical model to the Japanese case.

There is a variety of reasons why Japan has been in trouble for so long. On the one hand it is argued that Japan's deflation has been largely structural and that the money-transmission system has not been working because banks, saddled with bad loans, have not been able to lend more than they actually did. So the priority was initially to fix the banking system, and indeed several reforms affecting financial markets have been implemented in recent years. More recently, other structural reforms, most importantly a liberalization of the labor market, have been envisaged. On the other hand, an important role can be played by standard Keynesian economic policies such as expansionary fiscal and monetary measures, the implementation of which is however difficult due to a very large debt (240\% of GDP in 2014) and a nominal interest rate of zero since September 2010. Nevertheless, as we shall show below, a joint fiscal/monetary policy that reduces taxes and government spending and compensates the loss in tax revenue of the government by the Bank of Japan financing it can be devised and appears to be working. Furthermore, additional policies can be implemented by exploiting other standard Keynesian arguments, such as the introduction of downward nominal wage rigidities, or the creation of inflationary expectations. We shall explore these policies as well in the following subsections. 


\subsection{Fiscal and monetary policies}

A standard Keynesian argument is that a fiscal stimulus can boost demand when an economy is in a liquidity trap. Japan's public debt appears, however, to be too big already and thus to finance a fiscal stimulus in a conventional way does not seem possible. An alternative approach is to adopt quantitative easing. In fact, already in 2003 Ben Bernanke had suggested that the government enact tax cuts and the Bank of Japan finance them directly, paying for the forgone tax revenue to the government, so that the debt burden does not change. ${ }^{22}$

In the framework of our model we can emulate such a policy by reducing the tax rate from $t a x^{*}=0.5$ to a new value tax so that the income of (young) consumers out of profit after taxation is

$$
(1-\operatorname{tax}) \pi=\left(1-\operatorname{tax}^{*}\right) \pi+\Delta m,
$$

with

$$
\Delta m=\left(\operatorname{tax}{ }^{*}-\operatorname{tax}\right) \pi .
$$

Moreover, if the central bank pays for the reduction in consumers' taxes, the government's tax income is (as before)

$$
\operatorname{tax} \cdot \pi+\Delta m=\operatorname{tax}^{*} \cdot \pi .
$$

The government's budget deficit in real terms can then be written as

$$
G^{*}-t a x^{*} \cdot \pi=G^{*}-t a x \cdot \pi-\Delta m=\left(G^{*}-\Delta m\right)-t a x \cdot \pi .
$$

This is equivalent to a simultaneous balanced reduction in government spending to $G=G^{*}-\Delta m$ and in taxes.

${ }^{22}$ In this way the "Bank of Japan would mitigate the usual concerns about rising debt: debt purchases by the central bank rather than the private sector implies no net increase in debt service and hence no future tax increases. Consumers should then be more willing to spend rather than save any tax cut. It also gets around the Bank of Japan's concern about the blocked money-transmission mechanism: a joint monetary and fiscal boost will increase spending regardless of the health of banks" (The Economist, June 21st 2003, p. 74). 
What happens to the dynamic performance of the economy when the measure $(G, \operatorname{tax})$ is imposed? Starting from the quasistationary Keynesian unemployment state $(\bar{\alpha}, \bar{m}, \bar{\pi}, \bar{S}, \bar{\tau})$ given by (14) and setting government spending to $G=\operatorname{tax} \cdot \pi^{*}$, with $\pi^{*}=15$ being the Walrasian value of real profits, so that the government's budget is balanced at the Walrasian equilibrium, the result is displayed in Figure 6. The figure shows that a reduction in the tax rate monotonically increases the long-run stationary locally stable value of employment. Moreover, at a value of tax approximately equal to 0.17 , full employment is reached. Note that the horizontal lines in Figure 6 refer to the stationary employment values for $\operatorname{tax} \leq 0.17$ and $\operatorname{tax}=0.2,0.3, \ldots, 1$.

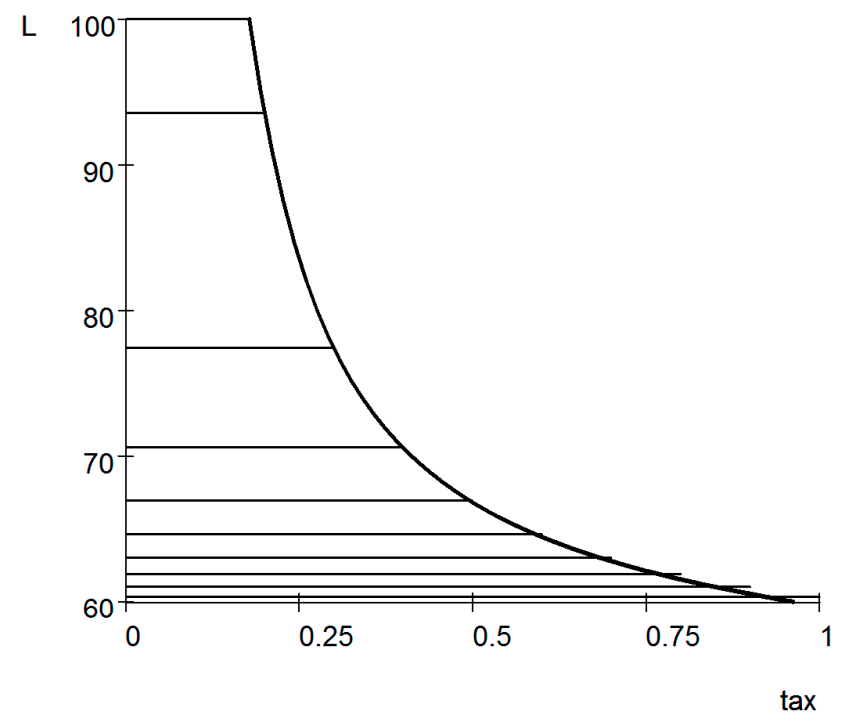

Figure 6: Stationary locally stable values of employment depending on different balanced-budget tax quotas.

The above policy measure is well known as balanced-budget fiscal policy, and textbook economics states that the corresponding 
balanced-budget multiplier is one. In particular, this would imply that a reduction in the tax rate (and in government spending) reduces output and hence employment. How is this compatible with Figure 6? Note, first of all, that the textbook multiplier refers to a static situation with prices and wages fixed whereas here we have a dynamic analysis with flexible prices, wages and money stock. To best understand what is going on, consider the two extreme cases of $(G, \operatorname{tax})=(0,0)$ and $(G, \operatorname{tax})=(15,1)$. Looking at the respective time series numbers, after one iteration we have in the first case an employment level of $\bar{L}_{1}=60.74$ whereas in the second case $\bar{L}_{1}=73.14$. Comparing with the initial level $\bar{L}=66.93$ (stationary at $\left.(G, \operatorname{tax})=\left(G^{*}, \operatorname{tax}^{*}\right)=(7.5,0.5)\right)$ these values fit quite well with the textbook prediction. Subsequently $\bar{L}_{t+1}>\bar{L}_{t}$ in the case $(G, \operatorname{tax})=(0,0)$ and $\bar{L}_{t+1}<\bar{L}_{t}$ in the case $(G, \operatorname{tax})=(15,1)$. The first time employment is larger in the first case than in the second is in period 8 when $\bar{L}_{8}=65.99$ in case $(G, \operatorname{tax})=(0,0)$ and $\bar{L}_{8}=65.97$ in case $(G, \operatorname{tax})=(15,1)$.

A further variable that helps to understand the dynamic behavior is the money stock $m$. In case $(G, \operatorname{tax})=(0,0), m$ increases monotonically from 33.37 in the first period to its limit 50, while in case $(G, \operatorname{tax})=(15,1) \mathrm{m}$ decreases monotonically from 30.5 to its limit 25.17. In the first case, the low (zero) tax enables young households to save more and carry more real balances to the second period of their life. This eventually increases aggregate demand more than the fixed reduction in government spending decreases it, thus increasing output and employment. The opposite is true in the case of the high tax: the decrease in real money balances eventually dominates the increase in government spending.

The above analysis suggests a balanced-budget tax reduction as a remedy to recession in the long run. However, the fact that in the short run employment falls below the already low stationary initial level is all but welcome. To avoid this, a simultaneous increase in the money stock $m_{0}$ can be used. Specifically, set $m_{0}=$ $\bar{m}+G^{*}-G$, together with $\left(\alpha_{0}, \pi_{0}, S_{0}\right)=(\bar{\alpha}, \bar{\pi}, \bar{S})$. If $(G, \operatorname{tax})=$ $(0,0)$, then $m_{0}=31.93+7.5=39.43$ and $\bar{L}_{1}=73.82$. Similarly, for 
less extreme values like for example $(G, \operatorname{tax})=(2.55,0.17), m_{0}=$ 36.88 and $\bar{L}_{1}=71.48$. In both cases, subsequent employment values increase monotonically to full employment. This shows that the combined measure of tax reduction and expansive monetary policy works well, also in the short run, in our model economy.

In the case of the Japanese economy, the Bernanke-type policy measure outlined at the beginning of this section is similar to the one just analyzed for our model economy. In fact, it consists of a tax reduction that does not change the debt burden of the government because the central bank pays the forgone tax revenue to the government. Thus more income is given to households increasing aggregate demand without changing the government's budget deficit. This is quite like what we have done in our model economy, where we have chosen a balanced-budget policy $(G, \operatorname{tax})$ with $\operatorname{tax}<\operatorname{tax}^{*}$ accompanied by a monetary policy $m_{0}=\bar{m}+G^{*}-G$. Figure 6 indicates, however, that the chosen tax reduction must be large enough as too small a reduction will improve but not eliminate unemployment. For example in our model economy, with $(G, \operatorname{tax})=(3,0.2)$ and $m_{0}=36.43, \bar{L}_{1}=71.07$ and the long-run stationary employment level is 93.59 .

\subsection{Expectations and downward nominal wage rigid- ity}

Expectations. In a series of papers and editorials of the end of the 1990s focusing on the Japanese deflationary recession, Paul Krugman argued that the best way to escape a liquidity trap was through the generation of inflationary expectations (see, e.g. Krugman, 1998). ${ }^{23}$ Although our paper does not offer insights on how to create inflationary expectations in the first place, it allows us to see whether they can help restoring full employment.

${ }^{23}$ There are several ways that could be imagined to create inflationary expectations. According to Krugman (1998), one way would be to apply a fiscal expansion that should be sustained even as the economy begins to develop inflation. For another example, the Bank of Japan can devaluate the Yen buying foreign currency, thereby increasing the prices of import goods. 
Starting from a deflationary recessionary stationary state $(\bar{\alpha}, \bar{m}, \bar{\pi}, \bar{S}, \bar{\tau})$ as the one depicted in Figure 1, we consider a change in $\tau$ from $\tau=h$ to $\tau=1$, that is we set $\left(\alpha_{0}, m_{0}, \pi_{0}, S_{0}, \tau_{0}\right)=$ $(\bar{\alpha}, \bar{m}, \bar{\pi}, \bar{S}, 1)$. This means that young consumers expect inflation for the next period and thus demand all their planned life-time consumption in the first period. This boosts aggregate demand and thus has the potential to lead the economy out of the recession. The result is shown in Figure 7 for $\nu_{1}=0.025$ and $\nu_{2}=0.1$ : the economy returns immediately to full employment and the inflationary expectations are confirmed. In fact, the percentage price inflation $\phi_{t}$ is positive over a prolonged period of time which means that the economy finds itself each period in a state of Repressed Inflation.

Krugman's recipe is thus confirmed in our setting. However, our analysis also highlights that nominal wage (and price) rigidities matter for the ability of inflationary expectations to restore full employment allowing the economy to overcome a liquidity trap. In particular, the situation illustrated above changes when a higher downward flexibility of the wage rate is assumed. This is shown in Figure 8 for $\nu_{1}=0.06$. The increase in aggregate demand due to the anticipated purchase of the consumption good is not sufficient to lead the economy out of recession, and expectations return after one period from inflationary to deflationary. Inflationary expectations would need to be sustained over time in order for the economy to recover from a deflationary recession. ${ }^{24}$

Recalling Figure 2, Figure 9 shows that expectations-formation works until the benchmark value of approximately $\nu_{1}=0.0525$ is reached. For $0.018<\nu_{1}<0.0525$ there is thus multiplicity of equilibria with self-confirming expectations.

Downward nominal wage rigidity. Finally, an additional policy in-

\footnotetext{
${ }^{24}$ For example, in the policy papers mentioned above, Krugman advocates an 'irresponsible' monetary policy - i.e. a monetary policy remaining expansionary even when prices start rising - to sustain inflationary expectations of sufficient persistence and magnitude to generate the needed inflation to overcome a liquidity trap.
} 
tervention that could be used to get over a deflationary recession is based on the 'control' of the downward adjustment of nominal wages. To see this, consider again a deflationary recessionary quasi-stationary state $(\bar{\alpha}, \bar{m}, \bar{\pi}, \bar{S}, \bar{\tau})$, but this time such a severe recession that generating inflationary expectations alone is not sufficient to exit from it. As we have seen in Figures 8 and 9, this is for example true for the quasi-stationary state obtained after the recessionary monetary shock when $\nu_{1}=0.06$, in which case $(\bar{\alpha}, \bar{m}, \bar{\pi}, \bar{S}, \bar{\tau})=(0.58,12.59,17.68,25.73,0.5)$, giving rise to the stationary values $(\bar{L}, \bar{Y})=(26.29,32.13)$. Now we take these values as new initial values, except that we change $\tau$ from $\bar{\tau}=0.5$ to $\tau_{0}=1$ and $\nu_{1}$ from 0.06 to $\nu_{1}=0$.

What happens is shown in Figure 10. At the beginning, the inflationary expectations fall back to deflationary ones as the effect of a constant nominal wage does not immediately generate enough additional purchasing power so as to overcome the aggregatedemand deficiency. However, as purchasing power builds up due to a falling goods price and hence an increasing real wage, after 23 periods the economy enters into a state of Classical Unemployment (excess demand on the goods market and excess supply on the labor market) and expectations switch endogenously to being inflationary. This pushes aggregate demand further up and fullemployment output is reached after 28 periods, when the economy enters into the regime of Repressed Inflation (excess demand on both markets). Thereafter the inflation rate decreases again and the economy eventually settles at the quasi-stationary inflationary state given by (15). The introduction of downward nominal wage rigidity, by increasing the real wage has reinforced households' purchasing power, which has rendered possible to exit from the recessionary state. ${ }^{25}$

\footnotetext{
${ }^{25}$ That, on the contrary, downward wage flexibility could impede to overcome the deflationary recession is consistent with the following quotation from The Economist (January 26th 2008, p.71): “... Japan's six-year recovery ... has been pulled along by exports, and despite repeated predictions, household spending has failed to take off. The reason is clear: though employment has steadily increased, wages are stagnant or falling ..."
} 

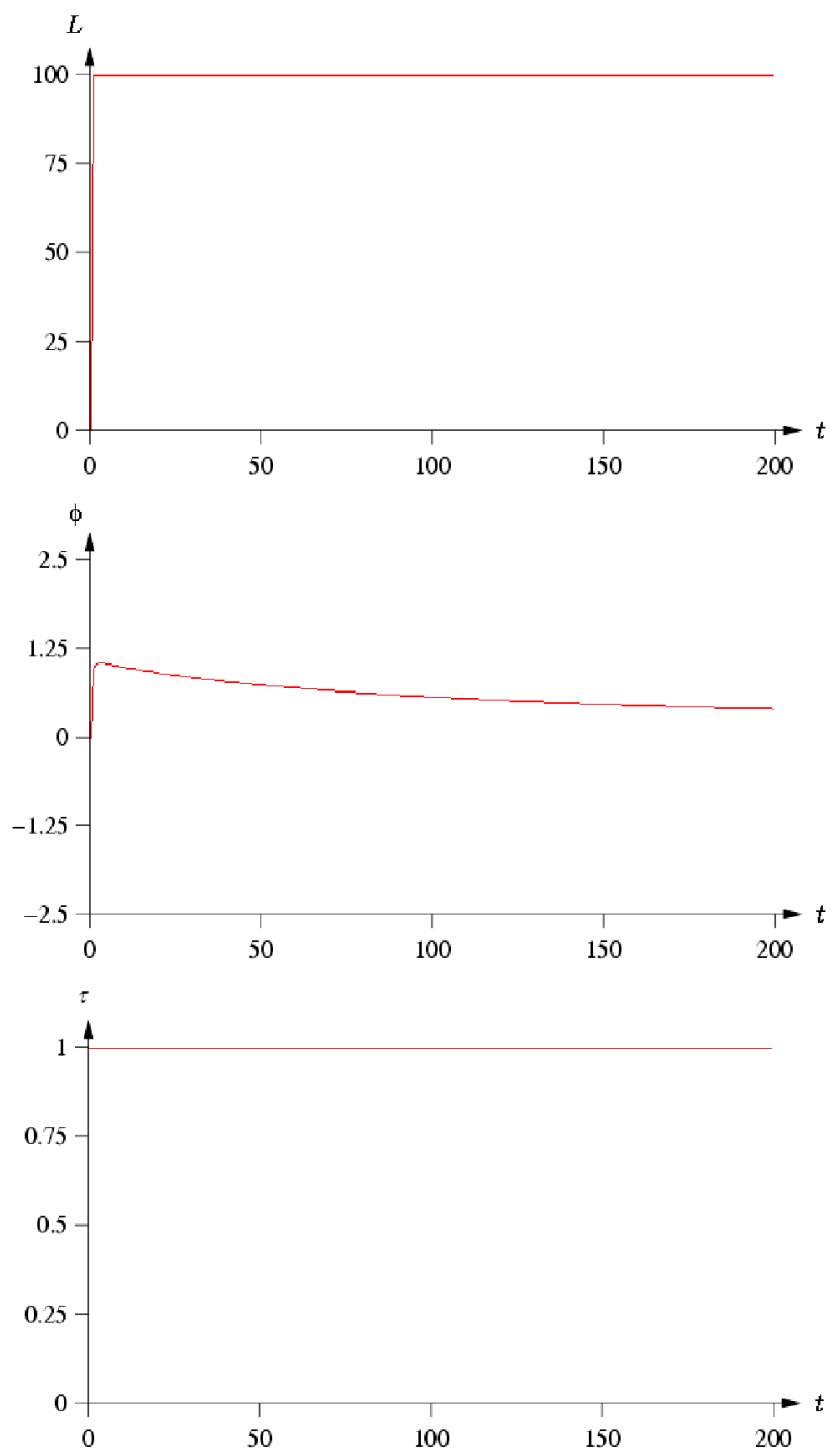

Figure 7: Effect of inflationary expectations if $\nu_{1}=0.025$. 

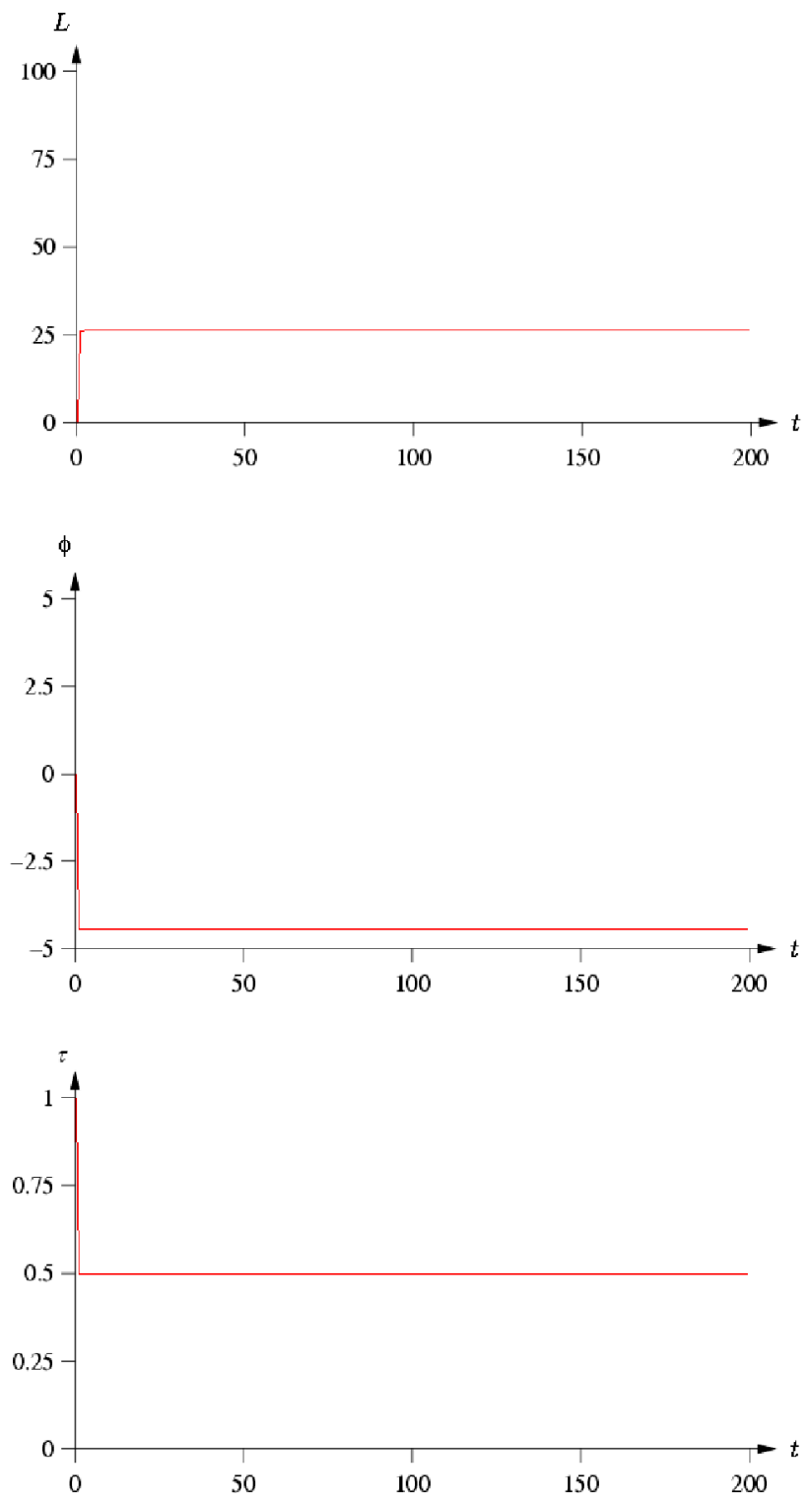

Figure 8: Effect of inflationary expectations if $\nu_{1}=0.06$. 


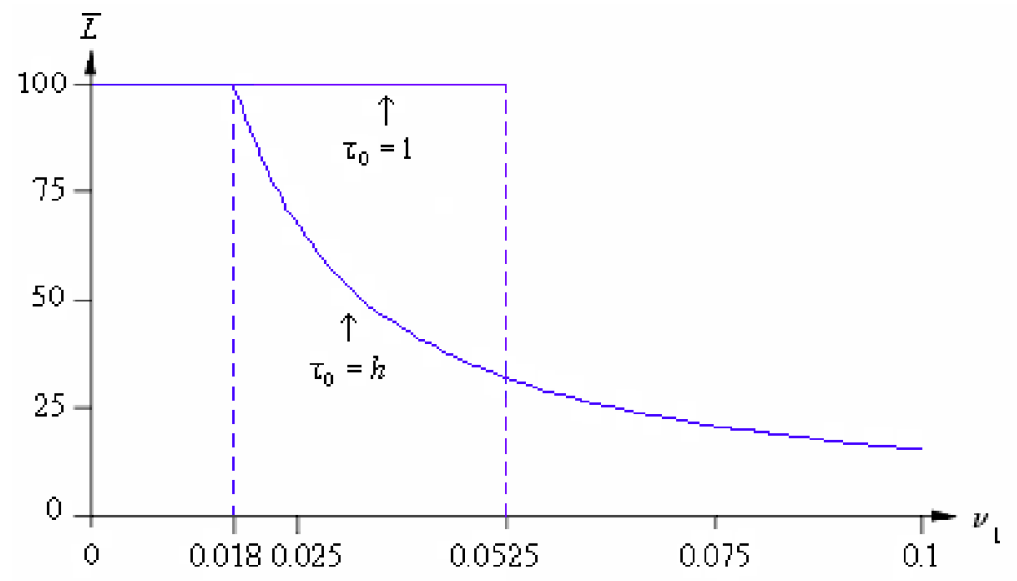

Figure 9: Multiplicity of equilibria with self-confirming expectations 

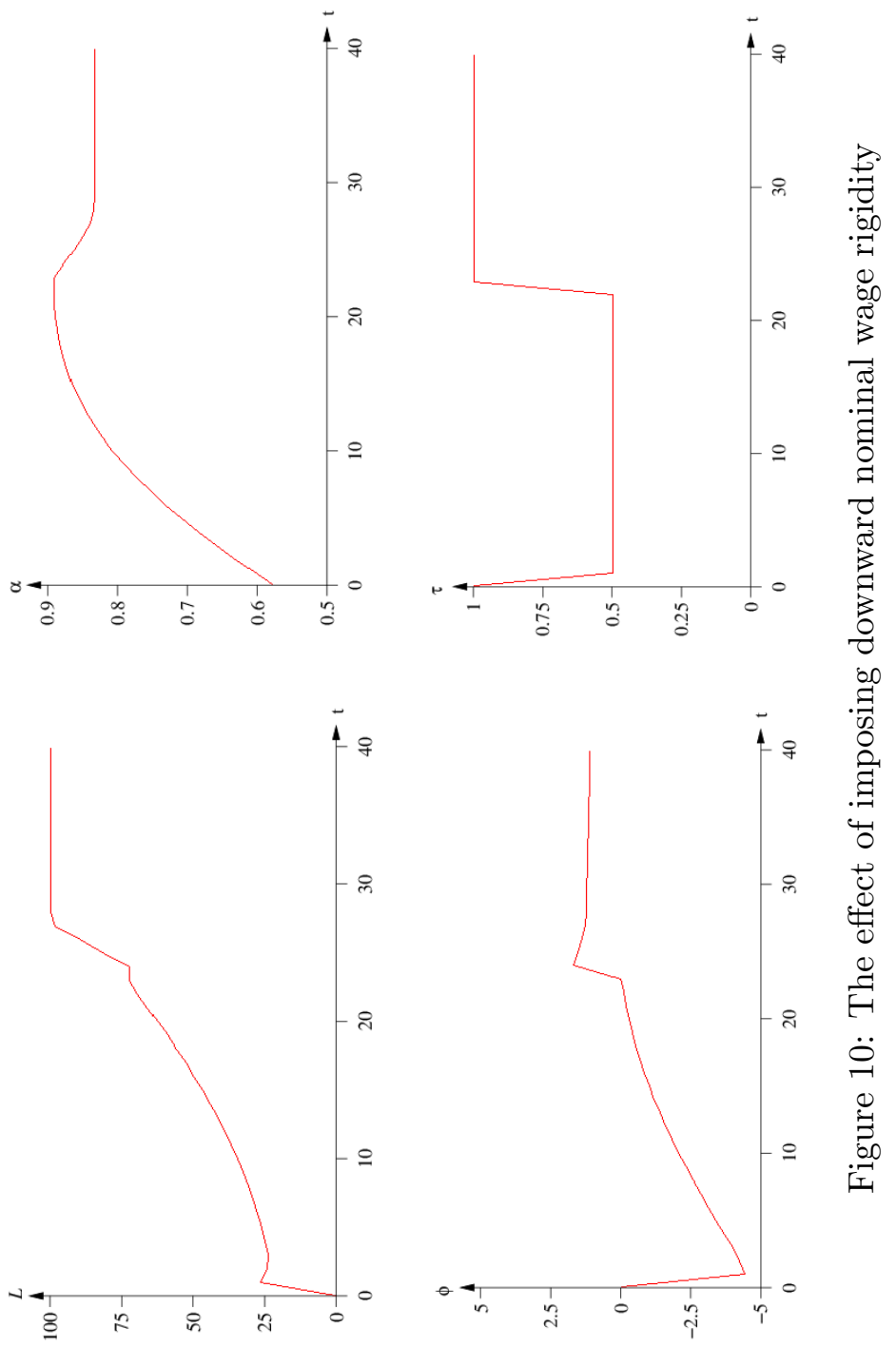


\section{Concluding remarks}

We have presented a non-tâtonnement dynamic macroeconomic model involving temporary equilibria with constant prices and stochastic rationing in each period, and price adjustment between periods. The model allows for trade also when prices are not at their market clearing levels, and consistent allocations are described in every period, giving rise at the same time to a well defined dynamics. This approach has enabled us to study, in a general-equilibrium setting, the dynamic functioning of an economy in which disequilibrium phenomena like underemployment, deflation/inflation and excess productive capacities are allowed to occur. These disequilibrium situations typically arise because the adjustment of prices to market imbalances is not instantaneous but proceeds with finite speed only; thus their functioning as an allocation device is imperfect, though not nil. As a consequence, quantity adjustments have to take place, which complement prices in their task of making trades feasible.

The fact that prices do, albeit not instantaneously, adjust in our model allows us to also work out the possible negative effects of too large a price and wage flexibility. If aggregate demand is insufficient, price and wage flexibility together with the possibility of a declining nominal money stock (due to government surpluses) may lead to a quasi-stationary situation in which there is permanent deflation of nominal variables but all real variables - among which most importantly employment - remain constant. This is so if the decrease in nominal money is proportional to the one in price and wage, because then the real stock of money held by consumers does not change. Thus it is possible that, in addition to the real wage, also the real wealth of households remains constant or, in other words, there is no real-balance effect. Vice versa, if the nominal wage is rigid downwards, then the real wage is eventually bound to increase, and aggregate-demand deficiency cannot persist in the long run.

As explained in the paper, the presence of inventories is deci- 
sive for these results to hold. Without them, labor demand does not diminish persistently enough in case of a recessionary shock to trigger a continuing fall in the nominal wage. In their presence, on the contrary, there is a sustained spillover from the goods market to the labor market that eventually translates into a permanent reduction of the real wage.

A further dynamic element in our model are consumers' expectations. Enabling them to store the good from their first to their second period of life, they anticipate future purchases when holding inflationary expectations. This has allowed us to study the role of expectations in the attempt to overcome a deflationary recession.

Numerical simulations of our dynamic system confirm that money is not necessarily neutral in the long run. Starting from a Walrasian equilibrium, a restrictive monetary shock can cause the economy to end up in a permanent recession, i.e. in a deflationary quasi-stationary Keynesian state in which employment and output are permanently below their Walrasian levels. Symmetrically, an expansionary monetary shock typically results in a quasi-stationary state of Repressed Inflation. Moreover, while our simulations suggest that the Walrasian equilibrium is locally unstable, the recessionary deflationary and the inflationary equilibria appear to be locally stable.

Our constructive approach to the modeling of expectations has rendered possible to obtain a truly forward dynamics in which there is multiplicity of self-confirming perfect-foresight equilibria depending on whether expectations are assumed to be deflationary or inflationary. If they are endogenized, endogenous switching between deflationary and inflationary guarantees that expectations are correct along any trajectory of the dynamic system.

In a policy perspective, we have used our framework to investigate possible remedies to deflationary recessions, focusing on a mix of fiscal and monetary policy similar to that recently implemented by the Japanese government and by the Bank of Japan, confirming that it points in the right direction for restoring full 
employment. In severe liquidity-trap situations, however, such a policy may be insufficient, and then the inducement of inflationary expectations should be considered as a further policy option. If they can effectively be generated, they will allow the economy to exit from the liquidity trap by boosting aggregate demand, provided the demand deficiency is not too dramatic. When this is the case the introduction of downward rigidity (and upward flexibility) of the nominal wage is a further useful measure as - with falling prices - it increases consumers' purchasing power and aggregate demand.

It is worth emphasizing that these results depend crucially on the possibility of modelling the quantity spillover effects between markets in disequilibrium, which in turn is rendered possible using as modelling strategy the non-tâtonnement approach and the adoption of the concept of equilibrium with stochastic quantity rationing.

\section{References}

Akerlof, G. A., 1980. "A Theory of Social Custom, of Which Unemployment May Be One Consequence", Quarterly Journal of Economics 94, 749-775.

Akerlof, G. A. and J. L. Yellen, 1985. "A Near-Rational Model of the Business Cycle with Wage and Price Inertia", Quarterly Journal of Economics 100, 823-838.

Auerbach, A. J. and M. Obstfeld, 2005. "The Case for OpenMarket Purchases in a Liquidity Trap", American Economic Review 95(1), 110-137.

Azariadis, C., 1975. "Implicit Contracts and Underemployment Equilibria", Journal of Political Economy 83, 1183-1202.

Baily, M. N., 1974. "Wages and Unemployment Under Uncertain Demand", The Review of Economic Studies 41, 37-50.

Ball, L. and D. Romer, 1990. "Real Rigidities and the NonNeutrality of Money", The Review of Economic Studies 57(2), 183-203. 
Ball, L. and D. Romer, 1991. "Sticky Prices as Coordination Failure", American Economic Review 81, 539-553.

Bénassy, J.-P., 1995, "Nominal Rigidities in Wage Setting by Rational Trade Unions", The Economic Journal, 105, 635-643.

Bental, B. and B. Eden, 1996. "Money and Inventories in an economy with Uncertain and Sequential Trade", Journal of Monetary Economics 37, 445-459.

Bernanke, B. and M. Gertler, 1989."Agency Costs, Net Worth and Business Fluctuations", American Economic Review 79, 1431.

Bernanke, B. and M. Gertler, 1995. "Inside the Black Box: The Credit Channel of Monetary Policy Transmission", Journal of Economic Perspectives IX, 27-48.

Bignami, F., L. Colombo and G. Weinrich, 2004. "Complex Business Cycles and Recurrent Unemployment in a Non-Walrasian Macroeconomic Model", Journal of Economic Behaviour and Organization 53, 173-191.

Blanchard, O.J., 1987. "Aggregate and Individual Price Adjustment", Brookings Papers on Economic Activity 1987-1, 57-109.

Blanchard, O.J., 1990. "Why Does Money Affect Output? A Survey", in B. Friedman and F. Hahn (eds.), Handbook of Monetary Economics, Amsterdam, North Holland.

Blanchard, O.J., 2000. "What Do We Know About Macroeconomics That Fisher And Wicksell Did Not?", Quarterly Journal of Economics, 1375-1409.

Blinder, A.S. and S. Fischer, 1981. "Inventories, Rational Expectations, and the Business Cycle", Journal of Monetary Economics 8, 277-304.

Blinder, A., 1982. "Inventories and Sticky Prices", American Economic Review 72, 334-348.

Böhm, V., 1989. Disequilibrium and Macroeconomics, New York, Basil Blackwell.

Böhm, V. and J. Wenzelburger, 1999, "Expectations, Forecasting, and Perfect Foresight. A Dynamical Systems Approach", Macroeconomic Dynamics, 3, 167-186. 
Calvo, G., 1983. "Staggered Prices in a Utility-maximizing Framework", Journal of Monetary Economics 12, 383-398.

Chiappori, P. and R. Guesnerie, 1991, "Sunspot Equilibria in Sequential Market Models", in: W. Hildenbrand and H. Sonnenschein (eds.), Handbook of Mathematical Economics, Vol. IV, Amsterdam: North-Holland.

Colombo L. and G. Weinrich, 2003. "The Phillips Curve as a Long-Run Phenomenon in a Macroeconomic Model with Complex Dynamics", Journal of Economic Dynamics and Control 28(1), $1-26$.

Diamond, P., 1982. "Aggregate Demand Management in Search Equilibrium", Journal of Political Economy XC, 881-894.

Gale, Douglas, 1979. "Large Economies with Trading Uncertainty" The Review of Economic Studies 46, 319-338.

Gale, Douglas, 1981. "Large Economies with Trading Uncertainty: a Correction", The Review of Economic Studies 48, 363364.

Grandmont, J.-M., 1985. "On Endogenous Competitive Business Cycles", Econometrica, 53, 995-1046.

Grandmont, J.-M. and G. Laroque, 1986. "Stability of Cycles and Expectations", Journal of Economic Theory, 40, 138-151.

Green, J., 1980. "On the Theory of Effective Demand", Economic Journal 90, 341-353.

Holmström, B. and J. Tirole, 1997. "Financial Intermediation, Loanable Funds, and the Real Sector", Quarterly Journal of Economics CXII, 663-692.

Holmström, B. and J. Tirole, 1998. "Private and Public Supply of Liquidity", Journal of Political Economy CVI, 1-40.

Honkapoja, S. and T. Ito, 1985. "On Macroeconomic Equilibrium with Stochastic Rationing", Scandinavian Journal of Economics 87(1), 66-88.

Kiyotaki, N., 1988. "Multiple Expectational Equilibria Under Monopolistic Competition", Quarterly Journal of Economics CII, 695-714.

Kiyotaki, N. and J. Moore, 1997. "Credit Cycles", Journal of 
Political Economy CV, 211-248.

Krugman, P., 1998. "It's Baaack: Japan's Slump and the Return of the Liquidity Trap", Brookings Papers on Economic Activity, 2, 137-187.

Mankiw, N.G., 1985. "Small Menu Costs and Large Business Cycles", Quarterly Journal of Economics 100, 529-537.

Romer, D.,1984. "The Theory of Social Custom: A Modification and Some Extensions", Quarterly Journal of Economics 99, 717-727.

Rotemberg, J.J. and G. Saloner, 1986. "A Supergame-Theoretic Model of Price Wars during Booms", American Economic Review 76, 390-407.

Rotemberg, J.J. and M. Woodford, 1991. "Markups and the Business Cycle", NBER Macroeconomics Annual, O. Blanchard and S. Fischer (eds.), Cambridge, MIT Press, 63-128.

Shapiro, C. and J. Stiglitz, 1984. "Equilibrium Unemployment as a Worker Discipline Device", American Economic Review 74, 433-444.

Solow, R., 1979. "Another Possible Source of wage Stickiness", Journal of Macroeconomics 1, 79-82.

Stiglitz, J.E., 1984. "Price Rigidities and Market Structure", American Economic Review 69, 350-355.

Svensson, L.E.O., "1980. Effective Demand and Stochastic Rationing", The Review of Economic Studies 47, 339-355.

Weinrich, G., 1982. "On the Theory of Effective Demand", Economic Journal 92, 174-175.

Weinrich, G., 1984. "On the Theory of Effective Demand under Stochastic Rationing", Journal of Economic Theory 34, 95115 .

Weinrich, G., 1988. "On the Foundations of Stochastic NonPrice Rationing and the Adjustment of prices", Decisions in Economics and Finance, 107-131.

Weinrich, G. 1997, "Endogenous Fixprices and Sticky Price Adjustment of Risk-Averse Firms", Journal of Economics 66, No. 3, 283-305. 


\section{Appendix 1}

Lemma A.1 When $b \leq 1-\sigma$, the solution to the firm's maximization problem is independent of the constraint $\ell_{t}^{d} \leq \frac{d_{t}}{\alpha_{t}}\left[f\left(\ell_{t}^{d}\right)+s_{t}\right]$.

Proof. The first order condition for an interior solution of the firm's problem is

$$
\gamma^{s} f^{\prime}(\ell)=\alpha \Leftrightarrow \gamma^{s} \frac{b f(\ell)}{\ell}=\alpha \Leftrightarrow \ell=\gamma^{s} \frac{b f(\ell)}{\alpha} .
$$

Moreover the inequalities $\frac{1}{b} \geq \frac{1}{1-\sigma} \geq \frac{1-\gamma^{s} \sigma}{1-\sigma}$ yield $1 \leq \frac{1-\sigma}{b\left(1-\gamma^{s} \sigma\right)}$. From this follows

$$
\ell \leq \frac{\gamma^{s}(1-\sigma)}{1-\gamma^{s} \sigma} \frac{1}{\gamma^{s}} \frac{1}{b} \ell=d \frac{1}{\gamma^{s}} \frac{1}{b} \ell=d \frac{1}{\gamma^{s}} \frac{1}{b} \gamma^{s} \frac{b f(\ell)}{\alpha}=\frac{d}{\alpha} f(\ell),
$$

which proves our claim.

\section{Proof of Proposition 1}

Since we hold $\left\{\alpha_{t}, m_{t}, \pi_{t}, S_{t}\right\},(G, \operatorname{tax})$ and $\tau$ fixed, we omit these variables whenever possible as arguments in the subsequent functions. Define the set

$$
\bar{H} \equiv\left\{\left(\lambda^{s} L^{s}, \gamma^{d} X^{d}\left(\lambda^{s}\right)\right) \mid\left(\lambda^{s}, \gamma^{d}\right) \in[0,1]^{2}\right\}
$$

and its subsets $\left.\bar{H}^{K} \equiv \bar{H}\right|_{\lambda^{s}<1, \gamma^{d}=1},\left.\bar{H}^{I} \equiv \bar{H}\right|_{\lambda^{s}=1, \gamma^{d}<1}, \bar{H}^{C} \equiv$ $\left.\bar{H}\right|_{\lambda^{s}<1, \gamma^{d}<1}$ and $\left.\bar{H}^{U} \equiv \bar{H}\right|_{\lambda^{s}=1, \gamma^{d}=1}$. Using the terminology introduced by Honkapohja and Ito (1985), we derive from these the consumption sector's trade curves

$$
\begin{aligned}
\bar{H}_{0}^{K} \equiv & \bar{H}^{K}+\left\{\left(0, m_{t}+G\right)\right\} \\
= & \left\{\left(\lambda^{s} L^{s}, X^{d}\left(\lambda^{s}\right)+m_{t}+G\right) \mid \lambda^{s} \in[0,1)\right\}, \\
\bar{H}_{0}^{I} \equiv & \left\{\left(L^{s}, \gamma^{d} X^{d}(1)+m_{t}+G\right) \mid \gamma^{d} \in(0,1)\right\} \\
& \cup\left\{\left(L^{s}, \delta m_{t}+G\right) \mid \delta \in(0,1]\right\} \cup\left\{\left(L^{s}, \varepsilon G\right) \mid \varepsilon \in[0,1]\right\},
\end{aligned}
$$




$$
\begin{aligned}
\bar{H}_{0}^{C} \equiv & \left\{\left(\lambda^{s} L^{s}, \gamma^{d} X^{d}\left(\lambda^{s}\right)+m_{t}+G\right) \mid\left(\lambda^{s}, \gamma^{d}\right) \in[0,1) \times(0,1)\right\} \\
& \cup\left\{\left(\lambda^{s} L^{s}, \delta m_{t}+G\right) \mid\left(\lambda^{s}, \delta\right) \in[0,1) \times(0,1]\right\} \\
& \cup\left\{\left(\lambda^{s} L^{s}, \varepsilon G\right) \mid\left(\lambda^{s}, \varepsilon\right) \in[0,1) \times[0,1]\right\}
\end{aligned}
$$

and

$$
\bar{H}_{0}^{U} \equiv \bar{H}^{U}+\left\{\left(0, m_{t}+G\right)\right\}=\left\{\left(L^{s}, X^{d}(1)+m_{t}+G\right)\right\} .
$$

Similarly, starting from

$$
\bar{F} \equiv\left\{\left(\lambda^{d} L^{d}\left(\gamma^{s}\right), \gamma^{s} Y^{s}\left(\lambda^{d}, \gamma^{s}\right)\right) \mid\left(\lambda^{d}, \gamma^{s}\right) \in[0,1]^{2}\right\}
$$

we define the production sector's trade curves as $\left.\bar{F}^{K} \equiv \bar{F}\right|_{\lambda^{d}=1, \gamma^{s}<1}$, $\left.\bar{F}^{I} \equiv \bar{F}\right|_{\lambda^{d}<1, \gamma^{s}=1},\left.\bar{F}^{C} \equiv \bar{F}\right|_{\lambda^{d}=1, \gamma^{s}=1}$ and $\left.\bar{F}^{U} \equiv \bar{F}\right|_{\lambda^{d}<1, \gamma^{s}<1}$. To derive these curves, we begin with noticing that

$$
\gamma^{s} Y^{s}\left(\lambda^{d}, \gamma^{s} ; \alpha_{t}, S_{t}\right)=\frac{\alpha_{t}}{b} \lambda^{d} L^{d}\left(\gamma_{t}^{s} ; \alpha_{t}\right)+\gamma^{s} S_{t}
$$

Indeed, by (5)

$$
\gamma^{s} Y^{s}\left(\lambda^{d}, \gamma^{s} ; \alpha_{t}, S_{t}\right)=\gamma^{s}\left[\lambda^{d} n^{\prime} f\left(\ell^{d}\left(\gamma_{t}^{s} ; \alpha_{t}\right)\right)+S_{t}\right]
$$

whereas from $f(\ell)=a \ell^{b}$ follows $f^{\prime}(\ell)=b \frac{f(\ell)}{\ell}$, which implies $f(\ell)=\frac{1}{b} f^{\prime}(\ell) \ell$. Therefore

$\gamma^{s} Y^{s}\left(\lambda^{d}, \gamma^{s} ; \alpha_{t}, S_{t}\right)=\gamma^{s}\left[\lambda^{d} n^{\prime} \frac{1}{b} f^{\prime}\left(\ell^{d}\left(\gamma_{t}^{s} ; \alpha_{t}\right)\right) \ell^{d}\left(\gamma^{s} ; \alpha_{t}\right)+S_{t}\right]$.

But $\gamma^{s} f^{\prime}\left(\ell^{d}\left(\gamma^{s} ; \alpha_{t}\right)\right)=\alpha_{t}$ from any producer's optimizing behavior, and thus

$$
\begin{aligned}
\gamma^{s} Y^{s}\left(\lambda^{d}, \gamma^{s} ; \alpha_{t}, S_{t}\right) & =\frac{\alpha_{t}}{b} \lambda^{d} n^{\prime} \ell^{d}\left(\gamma^{s} ; \alpha_{t}\right)+\gamma^{s} S_{t} \\
& =\frac{\alpha_{t}}{b} \lambda^{d} L^{d}\left(\gamma_{t}^{s} ; \alpha_{t}\right)+\gamma^{s} S_{t}
\end{aligned}
$$


This implies immediately that

$$
\bar{F}^{C}=\left\{\left(L^{d}\left(1 ; \alpha_{t}\right), \frac{\alpha_{t}}{b} L^{d}\left(1 ; \alpha_{t}\right)+S_{t}\right)\right\} .
$$

Consider now

$$
\bar{F}^{K}=\left\{\left(L^{d}\left(\gamma^{s} ; \alpha_{t}\right), \gamma^{s} Y^{s}\left(1, \gamma^{s} ; \alpha_{t}, S_{t}\right)\right) \mid \gamma^{s} \in[0,1)\right\} .
$$

Then (A.1) yields

$$
\gamma^{s} Y^{s}\left(1, \gamma^{s} ; \alpha_{t}, S_{t}\right)=\frac{\alpha_{t}}{b} L^{d}\left(\gamma_{t}^{s} ; \alpha_{t}\right)+\gamma^{s} S_{t} .
$$

On the other hand, (4) implies

$$
\gamma^{s}=\frac{\alpha_{t}}{a b}\left(\ell^{d}\left(\gamma_{t}^{s} ; \alpha_{t}\right)\right)^{1-b}=\frac{\alpha_{t}}{a b}\left(\frac{L^{d}\left(\gamma_{t}^{s} ; \alpha_{t}\right)}{n^{\prime}}\right)^{1-b}
$$

and therefore

$$
\gamma^{s} Y^{s}\left(1, \gamma^{s} ; \alpha_{t}, S_{t}\right)=\frac{\alpha_{t}}{b} L^{d}\left(\gamma_{t}^{s} ; \alpha_{t}\right)+\frac{\alpha_{t}}{a b}\left(\frac{L^{d}\left(\gamma_{t}^{s} ; \alpha_{t}\right)}{n^{\prime}}\right)^{1-b} S_{t}
$$

Since $L^{d}\left(\gamma_{t}^{s} ; \alpha_{t}\right)$ is strictly increasing in $\gamma_{t}^{s}$, this yields

$$
\bar{F}^{K}=\left\{\left(L, \frac{\alpha_{t}}{b} L+\frac{\alpha_{t}}{a b}\left(\frac{L}{n^{\prime}}\right)^{1-b} S_{t}\right) \mid 0 \leq L<L^{d}\left(1 ; \alpha_{t}\right)\right\} .
$$

Consider next

$$
\bar{F}^{I}=\left\{\left(\lambda^{d} L^{d}\left(1 ; \alpha_{t}\right), Y^{s}\left(\lambda^{d}, 1 ; \alpha_{t}, S_{t}\right)\right) \mid \lambda^{d} \in[0,1)\right\} .
$$

By (A.1) $Y^{s}\left(\lambda^{d}, 1 ; \alpha_{t}\right)=\frac{\alpha_{t}}{b} \lambda^{d} L^{d}\left(1 ; \alpha_{t}\right)+S_{t}$ and therefore

$$
\bar{F}^{I}=\left\{\left(L, \frac{\alpha_{t}}{b} L+S_{t}\right) \mid 0 \leq L<L^{d}\left(1 ; \alpha_{t}\right)\right\} .
$$

Since $\frac{\alpha_{t}}{a b}\left(\frac{L}{n^{\prime}}\right)^{1-b}=\gamma^{s} \leq 1, \bar{F}^{I}$ is positioned above $\bar{F}^{K}$. 


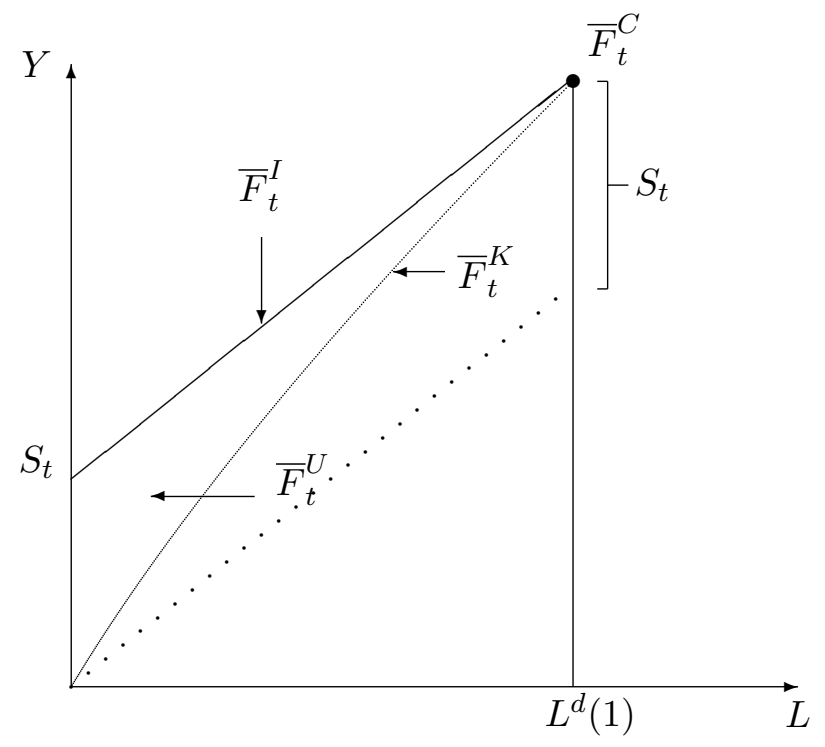

Figure 11: The producers' trade curves

Finally consider $\bar{F}^{U}$. It is given by

$$
\begin{array}{r}
\bar{F}^{U}=\left\{\left(\lambda^{d} L^{d}\left(\gamma^{s} ; \alpha_{t}\right), \frac{\alpha_{t}}{b} \lambda^{d} L^{d}\left(\gamma_{t}^{s} ; \alpha_{t}\right)+\frac{\alpha_{t}}{a b}\left(\frac{L^{d}\left(\gamma_{t}^{s} ; \alpha_{t}\right)}{n^{\prime}}\right)^{1-b} S_{t}\right)\right. \\
\left.\mid\left(\lambda^{d}, \gamma^{s}\right) \in[0,1)^{2}\right\}
\end{array}
$$

Comparing with $\bar{F}^{K}$ and $\bar{F}^{I}$, it is clear that $\bar{F}^{U}$ is the set of points contained between $\bar{F}^{K}$ and $\bar{F}^{I}$. Figure 11 illustrates the producers' trade curves.

Using the consumption sector's and the production sector's trade curves and indicating with $A^{c}$ the closure of the set $A$, we 
now note that a pair $(\bar{L}, \bar{Y}) \in \mathbb{R}_{+}^{2}$ is a temporary equilibrium allocation if and only if it is an element of the set

$$
\begin{aligned}
Z= & \left(\left(\bar{H}_{0}^{K}\right)^{c} \cap\left(\bar{F}^{K}\right)^{c}\right) \cup\left(\left(\bar{H}_{0}^{I}\right)^{c} \cap\left(\bar{F}^{I}\right)^{c}\right) \\
& \cup\left(\left(\bar{H}_{0}^{C}\right)^{c} \cap\left(\bar{F}^{C}\right)^{c}\right) \cup\left(\left(\bar{H}_{0}^{U}\right)^{c} \cap\left(\bar{F}^{U}\right)^{c}\right) .
\end{aligned}
$$

To show existence of an equilibrium is equivalent to showing that $Z$ is not empty. To this end consider first the locus

$$
\left(\bar{H}_{0}^{K}\right)^{c}=\left\{\left(\lambda_{t}^{s} L^{s}, X^{d}\left(\lambda_{t}^{s}\right)+m_{t}+G\right) \mid \lambda_{t}^{s} \in[0,1]\right\}
$$

and recall that

$$
X^{d}\left(\lambda_{t}^{s}\right)=\tau\left[(1-\operatorname{tax}) \pi_{t}+\alpha_{t} \lambda_{t}^{s} L^{s}\right] .
$$

Defining the function

$$
\Gamma_{t}(L)=\tau\left[(1-\operatorname{tax}) \pi_{t}+\alpha_{t} L\right]+m_{t}+G, L \geq 0,
$$

we see that $\left(\bar{H}_{0}^{K}\right)^{c}$ is the part of the graph of $\Gamma_{t}$ for which $L \leq L^{s}$.

Next consider again the production sector's trade curves. From (A.2) we conclude that the locus $\left(\bar{F}^{K}\right)^{c}$ is the part of the graph of the function

$$
\Delta_{t}(L)=\frac{\alpha_{t}}{b} L+\frac{\alpha_{t}}{a b}\left(\frac{L}{n^{\prime}}\right)^{1-b} S_{t}, L \geq 0,
$$

for which $L \leq L^{d}(1)$. Notice that the graphs of the functions $\Gamma_{t}$ and $\Delta_{t}$ always intersect. Indeed, $\Gamma_{t}^{\prime}(L)=\tau \alpha_{t}$ and $\Gamma_{t}(0)=$ $\tau(1-\operatorname{tax}) \pi_{t}+m_{t}+G>0$, whereas $\Delta_{t}^{\prime}(L) \geq \frac{\alpha_{t}}{b}>\tau \alpha_{t}$ (since $1 / b>1 \geq \tau)$ and $\Delta_{t}(0)=0$. Setting $\Delta_{t}(L)=\Gamma_{t}(L)$ yields (7) with the unique solution denoted $\widetilde{L}\left(\alpha_{t}, \pi_{t}, m_{t}, S_{t}, G, \operatorname{tax}, \tau\right)$. Therefore the equilibrium level on the labor market is

$$
\begin{aligned}
\bar{L}_{t} & =\min \left\{\widetilde{L}\left(\alpha_{t}, \pi_{t}, m_{t}, S_{t}, G, \operatorname{tax}, \tau\right), L^{d}\left(1, \alpha_{t}\right), L^{s}\right\} \\
& =\mathcal{L}\left(\alpha_{t}, \pi_{t}, m_{t}, S_{t}, G, \operatorname{tax}, \tau\right)
\end{aligned}
$$


whereas the one on the goods market is, by definition of the function $\mathcal{Y}(\cdot)$,

$$
\bar{Y}_{t}=\mathcal{Y}\left(\alpha_{t}, \pi_{t}, m_{t}, S_{t}, G, \operatorname{tax}, \tau\right) .
$$

This shows that the equilibrium allocation

$$
\left(\bar{L}_{t}, \bar{Y}_{t}\right)=\left(\mathcal{L}\left(\alpha_{t}, \pi_{t}, m_{t}, S_{t}, G, \operatorname{tax}, \tau\right), \mathcal{Y}\left(\alpha_{t}, \pi_{t}, m_{t}, S_{t}, G, \operatorname{tax}, \tau\right)\right)
$$

exists and is uniquely defined.

\section{Appendix 2: The complete dynamic system}

The dynamic system is given by four different subsystems, one for each of the equilibrium types $K, I, C$ and $U$, and endogenous regime switching. For given $(G, \operatorname{tax})$ and $\tau \in\{h, 1\}$, any list $\left(\alpha_{t}, \pi_{t}, m_{t}, S_{t}\right)$ gives rise to a uniquely determined equilibrium allocation $\left(\bar{L}_{t}, \bar{Y}_{t}\right)$ being of one of the above types (or of an intermediate one). More precisely, equation (6) allows us to characterize the type of equilibrium: if $\bar{L}_{t}=\widetilde{L}\left(\alpha_{t}, \pi_{t}, m_{t}, S_{t}, G, \operatorname{tax}, \tau\right)$, the resulting equilibrium is of type $K$ or a limiting case of it. If $\bar{L}_{t}=L^{d}\left(1, \alpha_{t}\right)$, type $C$ or a limiting case of it occurs. Finally, if $\bar{L}_{t}=L^{s}$, an equilibrium of type $I$ or a limiting case results if $\frac{\alpha_{t}}{b} L^{s}+S_{t} \leq \tau(1-\operatorname{tax}) \pi_{t}+\tau \alpha_{t} L^{s}+m_{t}+G$; otherwise the equilibrium is of type $U$. Regime switching may occur because $\left(\bar{L}_{t}, \bar{Y}_{t}\right)$ may be of type $T \in\{K, I, C, U\}$ and $\left(\bar{L}_{t+1}, \bar{Y}_{t+1}\right)$ of type $T^{\prime} \neq T$.

The above discussion and Proposition 1 allow us to determine the expressions of those rationing coefficients that are possibly smaller than one. This is summarized in the following corollary of Proposition 1.

Corollary A.1 In case $K, \lambda_{t}^{s}=\frac{\bar{L}_{t}}{L^{s}}$ and $\gamma_{t}^{s}=\frac{\alpha_{t}}{a b}\left(\frac{\bar{L}_{t}}{n^{\prime}}\right)^{1-b}$. In case $C, \lambda_{t}^{s}=\frac{\bar{L}_{t}}{L^{s}}$ and, in case $I, \lambda_{t}^{d}=\frac{L^{s}}{L^{d}\left(1, \alpha_{t}\right)}$. Moreover, in both these latter cases,

$$
\left(\gamma_{t}^{d}, \delta_{t}, \varepsilon_{t}\right)= \begin{cases}\left(\frac{\bar{Y}_{t}-m_{t}-G}{\tau(1-\operatorname{tax}) \pi_{t}+\tau \alpha_{t} \bar{L}_{t}}, 1,1\right) & \text { if } \bar{Y}_{t} \geq G+m_{t} \\ \left.0, \frac{\bar{Y}_{t}-G}{m_{t}}, 1\right) & \text { if } G+m_{t}>\bar{Y}_{t} \geq G \\ \left.0,0, \frac{\bar{Y}_{t}}{G}\right) & \text { if } \bar{Y}_{t}<G\end{cases}
$$


Finally, in case $U, \gamma_{t}^{s}=\frac{1}{S_{t}}\left(\bar{Y}_{t}-\frac{\alpha_{t}}{b} \bar{L}_{t}\right)$ and $\lambda_{t}^{d}=\bar{L}_{t} / L^{d}\left(\gamma_{t}^{s} ; \alpha_{t}\right)$.

Proof. We start with case $U$. Then, by (A.3) it must be true that

$$
\left(\bar{L}_{t}, \bar{Y}_{t}\right)=\left(\lambda^{d} L^{d}\left(\gamma^{s} ; \alpha_{t}\right), \frac{\alpha_{t}}{b} \lambda^{d} L^{d}\left(\gamma_{t}^{s} ; \alpha_{t}\right)+\frac{\alpha_{t}}{a b}\left(\frac{L^{d}\left(\gamma_{t}^{s} ; \alpha_{t}\right)}{n^{\prime}}\right)^{1-b} S_{t}\right) .
$$

Moreover by (4)

$$
L^{d}\left(\gamma^{s} ; \alpha_{t}\right)=n^{\prime}\left(\frac{\gamma_{t}^{s} a b}{\alpha_{t}}\right)^{\frac{1}{1-b}} .
$$

Therefore

$$
\frac{\alpha_{t}}{b} \lambda^{d} L^{d}\left(\gamma_{t}^{s} ; \alpha_{t}\right)+\frac{\alpha_{t}}{a b}\left(\frac{L^{d}\left(\gamma_{t}^{s} ; \alpha_{t}\right)}{n^{\prime}}\right)^{1-b} S_{t}=\bar{Y}_{t}
$$

$\Leftrightarrow$

$$
\frac{\alpha_{t}}{b} \lambda_{t}^{d} L^{d}\left(\gamma_{t}^{s} ; \alpha_{t}\right)+\gamma_{t}^{s} S_{t}=\bar{Y}_{t} .
$$

Recalling that $\lambda^{d} L^{d}\left(\gamma^{s} ; \alpha_{t}\right)=\bar{L}_{t}$ and solving for $\gamma_{t}^{s}$ yields the claimed expression.

In all cases, the values of $\lambda_{t}^{s}$ and $\lambda_{t}^{d}$ are immediate by definition. The value of $\gamma_{t}^{s}$ in case $K$ can be obtained using equation (4). Finally, $\gamma_{t}^{d}, \delta_{t}, \varepsilon_{t}$ are determined by means of Definition 1 and equations (1) and (2).

We can now give the explicit equations of all subsystems of the dynamic system.

Keynesian Unemployment system

Employment level: $\bar{L}_{t}=\widetilde{L}\left(\alpha_{t}, \pi_{t}, m_{t}, S_{t}, G, \operatorname{tax}, \tau\right)$.

Output level: $\bar{Y}_{t}=\frac{\alpha_{t}}{b} \bar{L}_{t}+\frac{\alpha_{t}}{a b}\left(\frac{\bar{L}_{t}}{n^{\prime}}\right)^{1-b} S_{t}$.

Rationing coefficients: $\lambda_{t}^{s}=\frac{\bar{L}_{t}}{L^{s}}, \lambda_{t}^{d}=1, \gamma_{t}^{s}=\frac{\alpha_{t}}{a b}\left(\frac{\bar{L}_{t}}{n^{\prime}}\right)^{1-b}$, $\gamma_{t}^{d}=1, \delta_{t}=\varepsilon_{t}=1$. 
Price inflation: $\theta_{t}=1-\mu_{1}\left(1-\gamma_{t}^{s}\right)$.

Real wage adjustment: $\alpha_{t+1}=\frac{1-\nu_{1}\left(1-\lambda_{t}^{s}\right)}{1-\mu_{1}\left(1-\gamma_{t}^{s}\right)} \alpha_{t}$.

Real profit: $\pi_{t+1}=\frac{1}{\theta_{t}}\left(\bar{Y}_{t}-\alpha_{t} \bar{L}_{t}\right)$.

Real money stock: $m_{t+1}=\frac{1}{\theta_{t}}\left[m_{t}+G+(1-\operatorname{tax}) \pi_{t}\right]-\pi_{t+1}$.

Inventories: $S_{t+1}=n^{\prime} a\left(\frac{a b \gamma_{t}^{s}}{\alpha_{t}}\right)^{\frac{b}{1-b}}+S_{t}-\bar{Y}_{t}$.

Repressed Inflation system

$\bar{L}_{t}=L^{s}$.

$\bar{Y}_{t}=\frac{\alpha_{t}}{b} \bar{L}_{t}+S_{t}$.

$\lambda_{t}^{s}=1, \lambda_{t}^{d}=\frac{L^{s}}{L^{d}\left(1, \alpha_{t}\right)} ; \gamma_{t}^{s}=1$.

If $\bar{Y}_{t} \geq G+m_{t}$, then $\gamma_{t}^{d}=\frac{\bar{Y}_{t}-m_{t}-G}{\tau(1-\operatorname{tax}) \pi_{t}+\tau \alpha_{t} \bar{L}_{t}}, \delta_{t}=\varepsilon_{t}=1$;

if $G+m_{t}>\bar{Y}_{t} \geq G$, then $\gamma_{t}^{d}=0, \delta_{t}=\frac{\bar{Y}_{t}-G}{m_{t}}, \varepsilon_{t}=1$;

if $\bar{Y}_{t}<G$, then $\gamma_{t}^{d}=\delta_{t}=0, \varepsilon_{t}=\frac{\bar{Y}_{t}}{G}$.

$\theta_{t}=1+\mu_{2}\left(1-\frac{\gamma_{t}^{d}+\delta_{t}+\varepsilon_{t}}{3}\right)$.

$\alpha_{t+1}=\frac{1+\nu_{2}\left(1-\lambda_{t}^{d}\right)}{1+\mu_{2}\left(1-\frac{\gamma_{t}^{d}+\delta_{t}+\varepsilon_{t}}{3}\right)} \alpha_{t}$.

$\pi_{t+1}=\frac{1}{\theta_{t}}\left(\bar{Y}_{t}-\alpha_{t} \bar{L}_{t}\right)$.

$m_{t+1}=\frac{1}{\theta_{t}}\left[\delta_{t} m_{t}+\varepsilon_{t} G+(1-\operatorname{tax}) \pi_{t}\right]-\pi_{t+1}$.

$S_{t+1}=\lambda_{t}^{d} n^{\prime} a\left(\frac{a b}{\alpha_{t}}\right)^{\frac{b}{1-b}}+S_{t}-\bar{Y}_{t}$.

Classical Unemployment System

$\bar{L}_{t}=L^{d}\left(1, \alpha_{t}\right)$.

$\bar{Y}_{t}=\frac{\alpha_{t}}{b} \bar{L}_{t}+S_{t}$.

$\lambda_{t}^{s}=\frac{\overline{L_{t}}}{L^{s}}, \lambda_{t}^{d}=1, \gamma_{t}^{s}=1$;

if $\bar{Y}_{t} \geq G+m_{t}$, then $\gamma_{t}^{d}=\frac{\bar{Y}_{t}-m_{t}-G}{\tau(1-\operatorname{tax}) \pi_{t}+\tau \alpha_{t} \bar{L}_{t}}, \delta_{t}=\varepsilon_{t}=1$;

if $G+m_{t}>\bar{Y}_{t} \geq G$, then $\gamma_{t}^{d}=0, \delta_{t}=\frac{\bar{Y}_{t}-G}{m_{t}}, \varepsilon_{t}=1$;

if $\bar{Y}_{t}<G$, then $\gamma_{t}^{d}=\delta_{t}=0, \varepsilon_{t}=\frac{\bar{Y}_{t}}{G}$. 


$$
\begin{aligned}
& \theta_{t}=1+\mu_{2}\left(1-\frac{\gamma_{t}^{d}+\delta_{t}+\varepsilon_{t}}{3}\right) . \\
& \alpha_{t+1}=\frac{1-\nu_{1}\left(1-\lambda_{t}^{s}\right)}{1+\mu_{2}\left(1-\frac{\gamma_{t}^{d}+\delta_{t}+\varepsilon_{t}}{3}\right)} \alpha_{t} \\
& \pi_{t+1}=\frac{1}{\theta_{t}}\left(\bar{Y}_{t}-\alpha_{t} \bar{L}_{t}\right) . \\
& m_{t+1}=\frac{1}{\theta_{t}}\left[\delta_{t} m_{t}+\varepsilon_{t} G+(1-\operatorname{tax}) \pi_{t}\right]-\pi_{t+1} . \\
& S_{t+1}=n^{\prime} a\left(\frac{a b}{\alpha_{t}}\right)^{\frac{b}{1-b}}+S_{t}-\bar{Y}_{t} .
\end{aligned}
$$

\section{Underconsumption}

$$
\begin{aligned}
& \bar{L}_{t}=L^{s} . \\
& \bar{Y}_{t}=\tau(1-\operatorname{tax}) \pi_{t}+\tau \alpha_{t} L^{s}+m_{t}+G . \\
& \lambda_{t}^{s}=1, \lambda_{t}^{d}=\frac{L^{s}}{L^{d}\left(\gamma_{t}^{s}, \alpha_{t}\right)}=\frac{\left(a b \gamma_{t}^{s}\right)^{1 /(1-b)} L^{s}}{n^{\prime} \alpha_{t}^{1 /(1-b)}} ; \\
& \gamma_{t}^{s}=\frac{\alpha_{t}}{a b}\left(\frac{\bar{L}_{t}}{n^{\prime}}\right)^{1-b}, \gamma_{t}^{d}=1, \delta_{t}=\varepsilon_{t}=1 . \\
& \theta_{t}=1-\mu_{1}\left(1-\gamma_{t}^{s}\right) . \\
& \alpha_{t+1}=\frac{1+\nu_{2}\left(1-\lambda_{t}^{d}\right)}{1-\mu_{1}\left(1-\gamma_{t}^{s}\right)} \alpha_{t} . \\
& \pi_{t+1}=\frac{1}{\theta_{t}}\left(\bar{Y}_{t}-\alpha_{t} \bar{L}_{t}\right) . \\
& m_{t+1}=\frac{1}{\theta_{t}}\left[m_{t}+G+(1-t a x) \pi_{t}\right]-\pi_{t+1} . \\
& S_{t+1}=\lambda_{t}^{d} n^{\prime} a\left(\frac{\gamma_{t}^{s} a b}{\alpha_{t}}\right)^{\frac{b}{1-b}}+S_{t}-\bar{Y}_{t} .
\end{aligned}
$$


Dipartimento di Discipline matematiche, Finanza matematica ed Econometria

Working Papers

\section{2}

12.1. CARSTEN KRABBE NIELSEN \& GERD WEINRICH, Bank Regulation when both Deposit Rate Control and Capital Requirements are Socially Costly, maggio 2012.

12.2. FAUSTO MIGNANEGO \& ALESSANDRO SBUELZ, Analytical cyclical price-dividend ratios, luglio 2012.

12.3. FEDERICA BARZI, FLAVIA CORTELEZZI, GIOVANNI MARSEGUERRA \& MARIA GRAZIA ZOIA, Cooperative innovation. Evidence from Italian firms, novembre 2012.

\section{3}

13.1 CLEMENTE GIAN PAOLO \& CORNARO ALESSANDRA, Lower Bounds for Kirchhoff Index: a Numerical Procedure, gennaio 2013.

13.2 WEDLIN ATTILIO, Processi stocastici "Jump-Diffusion": aspetti probabilistici, gennaio 2013. 
13.3 VALERIO POTİ \& MARIA GRAZIA ZOIA, Tailoring the logistic distribution to fit the empirical distribution of financial asset returns, febbraio 2013.

13.4 LAURA BARBIERI, FLAVIA CORTELEZZI, GIOVANNI MARSEGUERRA \& MARIA GRAZIA ZOIA, Technological status of the Italian companies, giugno 2013.

13.5 LUCA BAGNATO, LUCIO DE CAPITANI, ANGELO MAZZA \& ANTONIO PUNZO, SDD: An R package for Serial Dependence Diagrams, giugno 2013.

13.6 FLAVIA CORTELEZZI, GIOVANNI MARSEGUERRA, MASSIMILIANO RIGON \& MARIA GRAZIA ZOIA, Is collaboration with Universities really beneficial for firms? Evidence form Italy, giugno 2013.

13.7 NICOLÒ PECORA \& ALESSANDRO SPELTA, Macroeconomic stability and heterogeneous expectations, luglio 2013.

13.8 MICHELE LONGO \& ALESSANDRA MAININI, Portfolio Optimization Under Partial Information and CARA preferences, luglio 2013.

13.9 MICHELE LONGO \& ALESSANDRA MAININI, Portfolio Comparison with Complete and Partial Observation for a HARA Investor, luglio 2013. 


\subsection{LUCA BAGNATO, VALERIO POTİ \& MARIA GRAZIA}

ZOIA, Beyond the Gaussian law: the role of orthogonal polynomials, hyperbolic secant and logistic distributions in fitting with empirical evidence of financial asset returns, ottobre 2013.

\section{4}

14.1 DI SALVO ANGELO, Un'indagine di customer satisfaction nei servizi di factoring analizzata mediante il modello ad equazioni strutturali con variabili latenti, maggio 2014.

14.2 MARIO FALIVA, MARIA GRAZIA ZOIA, The family of power-raised hyperbolic secant distributions: moments, kurtosis, limit laws, luglio 2014.

14.3 LUCA COLOMBO, GERD WEINRICH, Expectations and Policies in Deflationary Recession, settembre 2014. 
Printed by

Gi\&Gi srl - Triuggio (MB)

September 2014 
